\title{
The diurnal evolution of the urban heat island of Paris: a model-based case study during Summer 2006
}

\author{
H. Wouters ${ }^{1,2}$, K. De Ridder ${ }^{1}$, M. Demuzere ${ }^{2}$, D. Lauwaet ${ }^{1}$, and N. P. M. van Lipzig ${ }^{2}$ \\ ${ }^{1}$ VITO, Flemish Institute for Technological Research, Department of Environmental and Atmospheric Modelling, Mol, \\ Belgium \\ ${ }^{2}$ KU Leuven, Department of Earth and Environmental Sciences, Leuven, Belgium
}

Correspondence to: H. Wouters (hendrik.wouters@vito.be)

Received: 11 June 2012 - Published in Atmos. Chem. Phys. Discuss.: 2 October 2012

Revised: 2 July 2013 - Accepted: 22 July 2013 - Published: 2 September 2013

\begin{abstract}
The urban heat island (UHI) over Paris during summer 2006 was simulated using the Advanced Regional Prediction System (ARPS) updated with a simple urban parametrization at a horizontal resolution of $1 \mathrm{~km}$. Two integrations were performed, one with the urban land cover of Paris and another in which Paris was replaced by cropland. The focus is on a five-day clear-sky period, for which the UHI intensity reaches its maximum. The diurnal evolution of the UHI intensity was found to be adequately simulated for this five day period. The maximum difference at night in $2 \mathrm{~m}$ temperature between urban and rural areas stemming from the urban heating is reproduced with a relative error of less than $10 \%$. The UHI has an ellipsoidal shape and stretches along the prevailing wind direction. The maximum UHI intensity of $6.1 \mathrm{~K}$ occurs at 23:00 UTC located $6 \mathrm{~km}$ downstream of the city centre and this largely remains during the whole night. An idealized one-column model study demonstrates that the nocturnal differential sensible heat flux, even though much smaller than its daytime value, is mainly responsible for the maximum UHI intensity. The reason for this nighttime maximum is that additional heat is only affecting a shallow layer of $150 \mathrm{~m}$. An air uplift is explained by the synoptic east wind and a ramp upwind of the city centre, which leads to a considerable nocturnal adiabatic cooling over cropland. The idealized study demonstrates that the reduced vertical adiabatic cooling over the city compared to cropland induces an additional UHI build-up of $25 \%$. The UHI and its vertical extent is affected by the boundary-layer stability, nocturnal low-level jet as well as radiative cooling. Therefore, improvements of representing these boundarylayer features in atmospheric models are important for UHI studies.
\end{abstract}

\section{Introduction}

Temperature tends to be higher in cities than in its natural surroundings, especially during the night (Landsberg, 1981; Oke, 1987; Arnfield, 2003). This is known as the urban heat island (UHI) effect. Urban surfaces distinguish themselves from their natural surroundings by particular urban surface characteristics like increased thermal inertia (Cai et al., 2008), a lowered vegetation cover and impervious land cover which reduces the evapotranspiration (Grimmond and Oke, 1999), a different albedo, emissivity and aerodynamic characteristics due to presence of streets and buildings. Together with the release of anthropogenic heat, this leads to the UHI effect reaching its maximum during the night. It is especially favoured by high solar irradiation (clear sky) during the preceding daytime period, no precipitation, low wind speeds and stable stratification. Under these conditions, a large amount of solar radiation reaches the surface, which is better transformed to heat, and subsequently retained as storage heat (Grimmond et al., 1999) for a longer time in urban areas compared to rural areas.

Accounting for the UHI is important when studying the effect of land-use change (e.g. forest to croplands, or vegetation cover to urban land) on climate on the mesoscale and global scale or to test mitigation strategies (e.g. Bowler et al., 2010; Dimoudi, 2003; Alexandri and Jones, 2007). In addition, the inclusion of urban effects can also serve to improve weather forecasts as shown in Hamdi et al. (2012). In this respect, it is indispensable to fully understand all the boundarylayer processes that contribute to the UHI.

The aim of this paper is to investigate the dominant heating terms that contribute to the maximum UHI intensity, and 
their interactions with boundary-layer processes and circulations. Therefore, two model runs are performed with the state-of-the-art atmospheric model ARPS (Xue et al., 2000, 2001) updated with a simple urban surface parametrization. The first run accounts for the current land use including the urbanization of Paris. For the second run, the urban land cover is replaced by cropland. By looking at the differential output between the two runs, the impact of urbanization on the surface energy balance, the consequential UHI and its vertical extent are analysed. Even though the surface energy balance of the urban surface and the consequential boundary-layer UHI has already been addressed in earlier studies, such as Lemonsu and Masson (2002), their direct interaction with the nocturnal boundary layer have not been investigated in detail. It is known that the mixed-layer height is at least eight to ten times smaller during the night than during the day so that urban heat release is mixed over a significantly smaller depth (Bohnenstengel et al., 2011). Yet, the direct link between the urban surface heating and nocturnal increase in boundary-layer UHI intensity has not been investigated. The interaction of urban surface heating with nocturnal boundary-layer stability, near-surface radiative cooling, low-level circulations such as the low-level jet and the vertical motion induced by orography have not been addressed as well. Moreover, the representation of these boundary-layer features during the night remains a challenge in state-of-theart atmospheric models. It is not known to what extent these uncertainties affect the representation of the UHI at that time. In order to address these questions, an idealized advection model is developed in which a moving air column is advected over the city during the night. The model is used to study the underlying mechanisms that favour a maximum boundarylayer UHI build-up at night even though the urban surface heating is relatively low at that time. In addition, it is investigated how the UHI extends in the vertical under nocturnal boundary conditions. The idealized advection model also allows to determine the interaction of urban surface heating with boundary-layer features including orographical effects, the low-level jet, radiation cooling and stability. Therefore, it provides insight to which extent uncertainties of the nocturnal boundary layer affects the representation of the UHI.

The structure of the paper is as follows. The methodology section consists of the description of the atmospheric model and its configuration (Sect. 2.1) and the theoretical background of the idealized boundary-layer advection model (Sect. 2.2). The results for a 5-day period for which the UHI reaches its maximum are presented in Sect. 3. Hereby, we start with the evaluation of a reference run with the ARPS model results and UHI intensity (Sect. 3.1). Afterwards, the different contributions of urbanization to urban surface heating and their relative importance for the development of the UHI intensity are investigated by analyzing the surface energy balance (SEB) in Sect. 3.2. The spatial extent of the maximum UHI intensity in the horizontal and vertical for Paris are analysed in Sect. 3.3. We apply the idealized ad- vection model (Sect. 3.4) for an in-depth analysis of the evolution of the boundary layer over the city during the night. Hereby, the sensitivity of the nocturnal UHI build-up to the different boundary-layer processes and stability are investigated. Our conclusions are formulated in Sect. 4.

\section{Method}

\subsection{Mesoscale model description and set-up}

Meteorological fields are simulated using the Advanced Regional Prediction System (ARPS), a non-hydrostatic mesoscale atmospheric model developed at the University of Oklahoma (Xue et al., 2000, 2001). The turbulent fluxes of momentum and sensible heat are calculated by accounting for stability effects and the roughness sublayer (Garratt, 1992). Therein, flux-profile relationships for wind speed and temperature from Cheng and Brutsaert (2005), Businger (1966) or Dyer (1967), and De Ridder (2010) are used. These flux-profile functions are solved for $\zeta=z / L$ iteratively $(z$ is the lowest model layer height above the displacement height and $L$ the Obukhov Length) by establishing a relation involving the bulk Richardson number $R i_{\mathrm{B}}$ (Arya, 2001), and using Ridders (1979) root finding scheme as described in Press et al. (1992). The land-surface scheme used in these simulations is that of De Ridder and Schayes (1997), which contains advanced parametrizations of plant transpiration. Temperature and water content of the vegetation canopy and of five soil layers are calculated using prognostic conservation equations, and water flow in the soil is calculated using Richard's equation (Garratt, 1992). Soil moisture and temperature were initialized using data from the Global Land Data Assimilation System (GLDAS see Rodell et al., 2004). For reasons of consistency, the soil texture taken was the same as that used in GLDAS. From the soil texture information that comes with the GLDAS data, we estimated domain-mean fractions of clay, sand, and silt, with contributions of 25,35 , and $40 \%$, respectively. The corresponding soil textural parameters of the Clapp and Hornberger (1978) relations used in our model are based on Cosby et al. (1984). It should be noted that, even though the soil moisture simulation is not directly relevant to anthropogenic urban materials such as concrete and asphalt, it does influence the urban-rural temperature difference, which is the focus of this study, hence the care taken here to properly simulate this quantity.

The land-surface scheme was extended to represent urban surfaces as described in Demuzere et al. (2008). The main feature of that extension is the use of Zilitinkevich (1970) thermal roughness length parametrization in urban areas, the thermal inertia which is assigned a value of $1800 \mathrm{~J} \mathrm{~m}^{-2} \mathrm{~s}^{-1 / 2} \mathrm{~K}^{-1}$, and the inclusion of anthropogenic heating. The latter was specified as in Demuzere et al. (2008) for Marseille, though scaled up for Paris. In Demuzere et al. (2008), the estimated anthropogenic heat flux for Marseille 


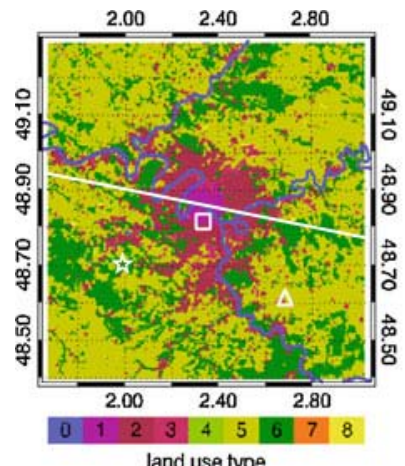

land use type
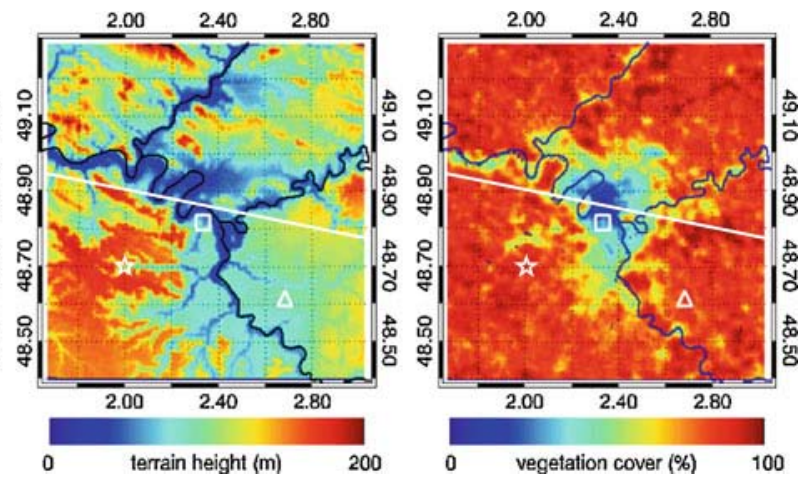

Fig. 1. Land-use types (left), terrain height (middle) and vegetation cover (right) of the Paris $1 \mathrm{~km}$ simulation domain. The different land-use types are defined as water (0), urban (1), sub-urban (2), industrial (3), grass(4), crops (5), forest (6), snow/ice (7), shrubs (8). The rectangular and the triangular box represent the locations of the urban (Paris-Montsouris, square) and rural (Melun, triangle) stations, respectively. The star indicates the location of the radio soundings at Trappes. The line indicates the vertical transect along the prevailing east wind in the base run used for the vertical profile analysis.

was found to vary between approximately $15 \mathrm{~W} \mathrm{~m}^{-2}$ (night) and $30 \mathrm{~W} \mathrm{~m}^{-2}$ (day), with a linear transition between these two values during the morning and evening hours. The detailed time profile is shown in Fig. 10 of Demuzere et al. (2008). The scaling up for Paris was achieved using observed satellite-based anthropogenic light irradiance (visible nocturnal lights from space). As explained in Makar et al. (2006), such information can be related to the annual mean anthropogenic heat flux. While for Marseille the estimated annual mean anthropogenic heat amounts to $28.8 \mathrm{~W} \mathrm{~m}^{-2}$, for Paris this value reaches $59.6 \mathrm{~W} \mathrm{~m}^{-2}$ (see http://www.iiasa. ac.at/Research/TNT/WEB/heat/). The diurnal anthropogenic heat flux over Paris were obtained applying this ratio of 2.07 $(=59.6 / 28.8)$ to that of Marseille.

Aerodynamic roughness length, albedo, emissivity, and the unconstrained stomatal resistance were specified as a function of land-use type, which was interpolated from the CORINE land-cover map (European Commission 1994), see Fig. 1. Terrain height was interpolated from the Global 30 Arc Second Elevation dataset (GTOPO30) distributed by the US Geological Survey. Sea-surface temperature was derived from MODIS thermal imagery. The vegetation abundance was specified as a linear function of normalized difference vegetation index (NDVI) values interpolated from satellite imagery of the VEGETATION instrument onboard the SPOT satellite platform, following relations established by Wittich and Hansing (1995) and Gutman and Ignatov (1998).

The land-surface scheme employs the mosaic approach, allowing different land-use types to co-exist within a surface grid cell. The surface energy balance is computed individually for each land-use class, and the energy flux for each grid cell is calculated as the weighted average.

We employ a three-level one-way grid nesting at horizontal resolutions of $16,4,1 \mathrm{~km}$. Each of the nesting domains was run in a configuration of 100 by 100 grid cells in the horizontal direction, and 35 levels in the vertical direction, with vertical resolution starting at $25 \mathrm{~m}$ near the surface to approximately $1 \mathrm{~km}$ near the model top located at an altitude of $15 \mathrm{~km}$. The $1 \mathrm{~km}$ model domain chosen for the simulation is the larger area of Paris, as shown in Fig. 1. The $16 \mathrm{~km}$ simulation was forced at its lateral boundaries by 6-hourly analysis fields from the operational model of the European Centre for Medium Range Weather Forecasting (ECMWF), available at a spatial resolution of $0.25^{\circ}$ in latitude and longitude.

The model set-up and configuration is applied for the period of the 1 to 13 June 2006 and is the same as from the model configuration used in Sarkar and De Ridder (2010). This run is hereafter referred to as the "base run". The period is characterized by calm weather, low wind speeds, limited cloud and precipitation and strong temperature inversion during the night, which all favour the development of the urban heat island.

Besides the base run, an additional scenario run is performed during the same period for which the model set-up is exactly the same, except that the urban and sub-urban fractions have been replaced by crops. For the concerned areas, obviously no NDVI satellite data is available, so the specification of vegetation abundance is problematic. To tackle this problem, an image-processing technique is used. The basic idea is to determine vegetation abundance from a probability distribution for crops that corresponds to the one from the current-day situation. Furthermore, a Lee (1986) smoothing filter and a sharpening filter (Jain, 1989) are applied subsequently to get a realistic map for the vegetation abundance. More details of this data generation procedure can be found in Van Weverberg et al. (2008).

The urban heat island is estimated from the difference in output between the two runs. We are interested in a time span of maximum urban surface heating, i.e. for meteorological conditions that favour a strong UHI effect. As the heat island intensity evolves from modest to high values over the course 
of the period during 1 to 13 June both in the observations as in the model results, a period is selected for which the overall temperature difference between the base run and the scenario run is the highest. These conditions occur during the second half of the model run, namely during a 5-day period between 8 June and 13 June.

\subsection{Idealized boundary-layer advection model}

In order to get better insight in the development of the nocturnal boundary-layer UHI, an idealized Lagrangian singlecolumn advection model is developed. Hereby, an air column that moves along the prevailing east wind is considered. This model takes into account the nocturnal surface sensible heat flux $\left(\overline{w^{\prime} \theta^{\prime}}\right)_{0}$, the initial boundary-layer profile upwind of the city and vertical wind $w_{h}$. It will be used in Sect. 3.4 to analyse the evolution of the boundary layer during the night over urban areas, and to investigate how the much smaller nocturnal surface sensible heat flux of the city compared to the day is able to increase the UHI intensity and reaches its maximum at that time. One needs to make a distinction between upward and downward surface sensible heat flux. Therefore, sets of equations for the convective boundary layer (CBL) with surface heating and for the nocturnal (stable) boundary layer (NBL) with surface cooling are considered in Sects. 2.2.1 and 2.2.2, respectively.

\subsubsection{Slab model for the convective boundary layer}

For the CBL, the slab model from Garratt (1992) is used. It extended to account for a constant vertical velocity at the top of the CBL (Fig. 2) as demonstrated in Sect. 3.4.3.

The temperature $\theta$ of the mixed layer changes due to the upward surface sensible heat flux which is distributed over the mixer-layer height $h_{e}$ :

$\frac{\mathrm{d} \theta}{\mathrm{d} t}=\frac{\left(\overline{w^{\prime} \theta^{\prime}}\right)_{0}}{h_{e}}$.

The mixer-layer height increases due to vertical advection of potential temperature and temperature increase:

$\frac{\mathrm{d} h_{e}}{\mathrm{~d} t}=w_{h}+\frac{1}{\gamma} \frac{\mathrm{d} \theta}{\mathrm{d} t}$,

where $\gamma$ is the temperature slope of the stable temperature profile above the mixer layer, and $w_{h}$ is the vertical wind speed at the mixed-layer height. This set of equations lead to a transcendental differential equation in $h_{e}$ :

$\frac{\mathrm{d} h_{e}}{\mathrm{~d} t}=\frac{\left(\overline{w^{\prime} \theta^{\prime}}\right)_{0}}{\gamma h_{e}}+w_{h}$,

which can be solved with the Newton-Raphson numerical method (see Appendix B). Afterwards, the evolution of the temperature can be integrated from Eq. (2):

$\theta(t)=\theta(0)+\gamma\left(h_{e}(t)-h_{e}(0)\right)-\gamma w_{h} t$.

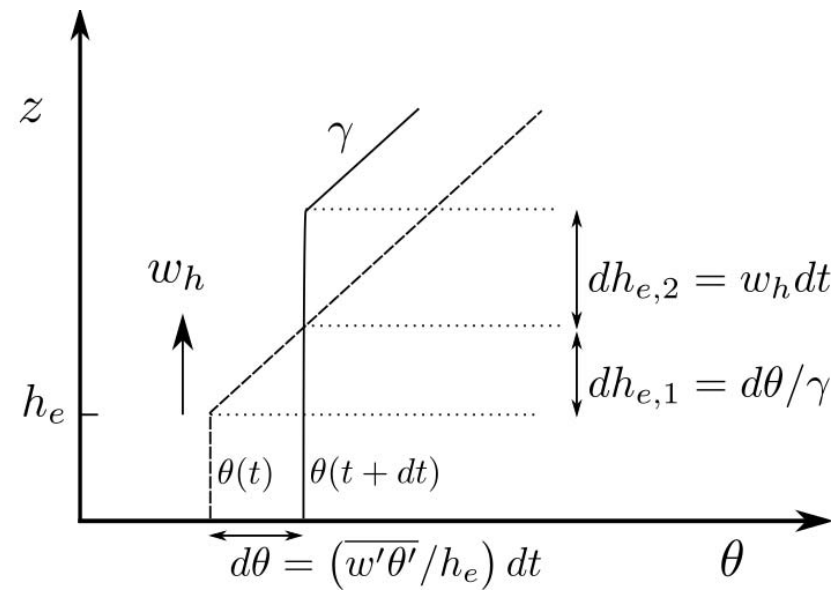

Fig. 2. The evolution of the vertical potential temperature profiles for the CBL as a function of height $z$. The vertical velocity is indicated with $w_{h} . \mathrm{d} \theta$ represents the mixed-layer temperature change due to the surface heat flux $\left(\overline{w^{\prime} \theta^{\prime}}\right) \cdot \gamma$ is the temperature slope above the mixed-layer height $h_{e} . \mathrm{d} h_{e, 1}$ and $\mathrm{d} h_{e, 2}$ are the changes in mixed-layer height due to the surface sensible heat flux and vertical velocity. The thick dashed line depicts the temperature profile time $t$, and the full lines that of a time step $\mathrm{d} t$ later. $\theta(t)$ and $\theta(t+\mathrm{d} t)$ are the corresponding mixed-layer temperatures.

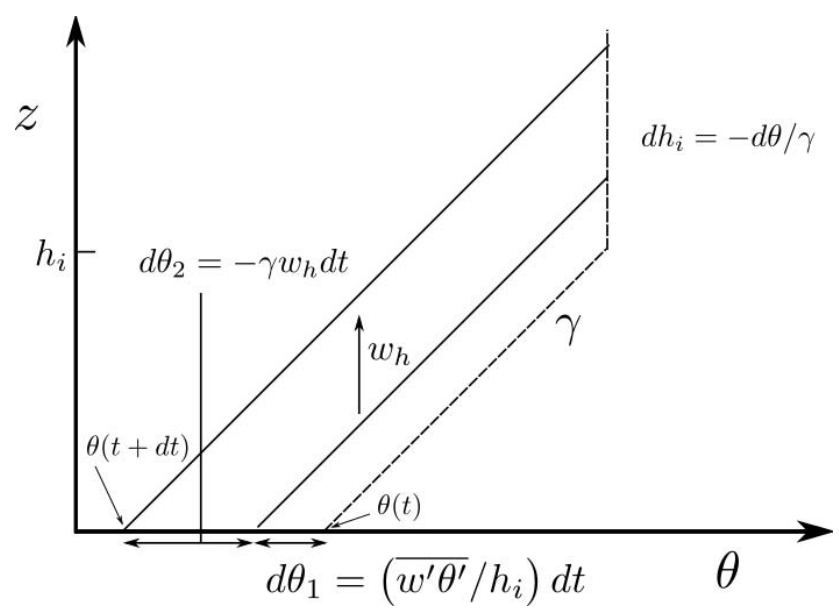

Fig. 3. The same as in Fig. 2, but for the the NBL. $h_{i}$ is the inversion height. $\mathrm{d} h_{i}$ is the change in inversion height due to surface sensible cooling and upward motion. The temperature changes at the surface due to negative surface sensible flux and upward motion are indicated with $\mathrm{d} \theta_{1}$ and $\mathrm{d} \theta_{2}$, respectively.

\subsubsection{Slab model for the nocturnal boundary layer}

In case surface cooling occurs, an NBL model can be applied based on Garratt (1992), Eq. (6.74) in Sect. 6.2.6. Such an inversion-layer model is illustrated in Fig. 3.

The potential temperature at the surface $(\theta)$ changes due to the surface cooling which decreases the temperature homogeneously up to the inversion height $h_{i}$, and due to vertical 

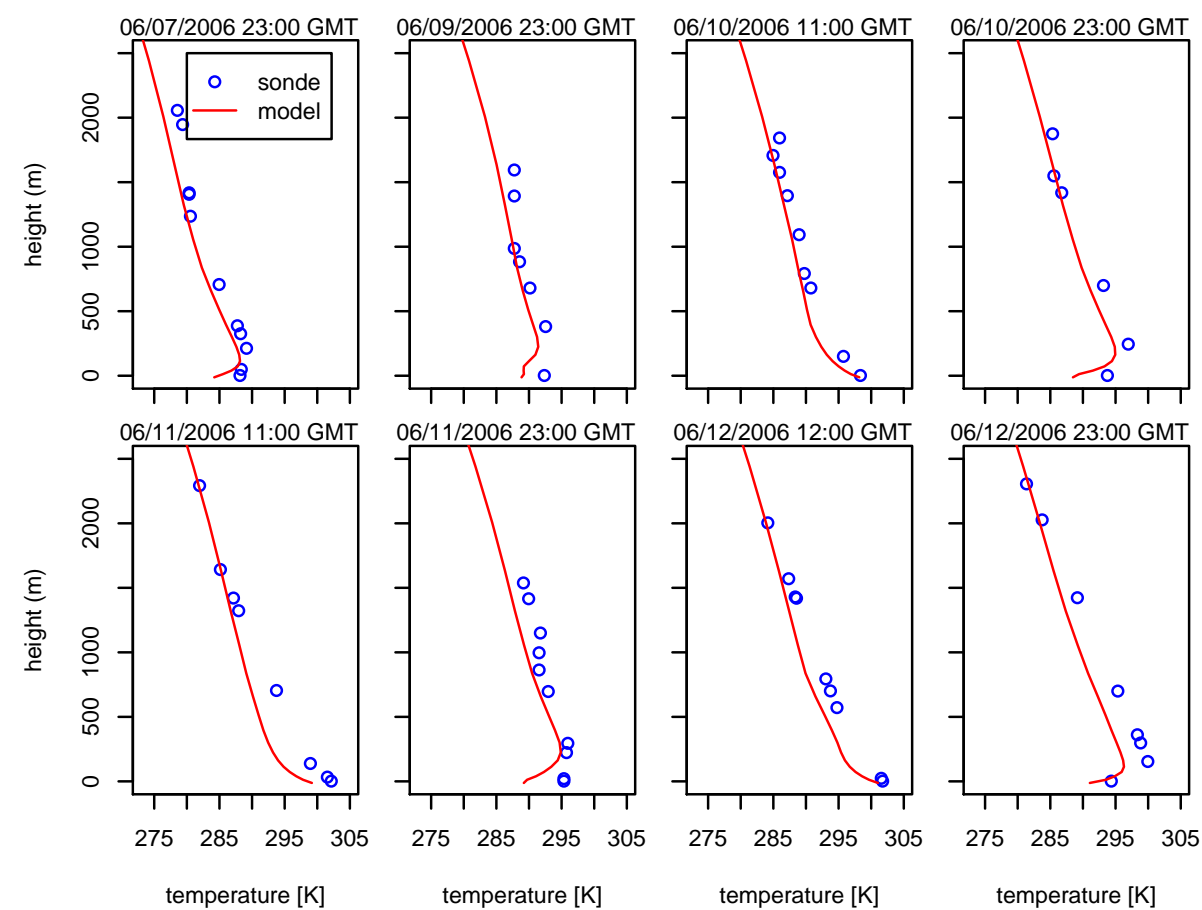

temperature $[\mathrm{K}]$

temperature $[\mathrm{K}]$

temperature $[\mathrm{K}]$

Fig. 4. Comparison between radio soundings and model output (base run) at Trappes during the selected 5-day period of clear-sky conditions

advection of potential temperature which vertically shifts the temperature profile:

$$
\begin{aligned}
\frac{\mathrm{d} \theta}{\mathrm{d} t} & =\frac{\left(\overline{w^{\prime} \theta^{\prime}}\right)_{0}}{h_{i}}-\gamma w_{h} \\
\frac{\mathrm{d} h_{i}}{\mathrm{~d} t} & =-\frac{1}{\gamma} \frac{\mathrm{d} \theta}{\mathrm{d} t},
\end{aligned}
$$

where $w_{h}$ is the vertical wind speed at the inversion height. Eq. (5) covers the following physical processes: the surface cooling cools the stable layer homogeneously up to the inversion height $h_{i}$ (first term), and vertical advection of potential temperature vertically shifts the temperature profile. The fact that the temperature slope remains the same, is expressed by Eq. (6), so that a change in $h_{i}$ is related to a change in temperature $\theta$ at the surface. This set of equations can be converted to a differential equation for the inversion height:

$$
\frac{\mathrm{d} h_{i}}{\mathrm{~d} t}=\frac{-\left(\overline{w^{\prime} \theta^{\prime}}\right)_{0}}{\gamma h_{i}}+w_{h}
$$

It can be solved in a similar way as the CBL model equations. Again, the temperature evolution follows from integration of Eq. (6):

$$
\theta(t)=\theta(0)-\gamma\left(h_{i}(t)-h_{i}(0)\right) .
$$

\section{Results}

\subsection{Model evaluation}

In this section, the ARPS model results are evaluated for the selected week of maximum urban surface heating between 8 June 2006 (00:00 UTC) and 13 June 2006 (00:00 UTC). Radio soundings of temperature profiles, and $2 \mathrm{~m}$ temperature ground measurements including the urban/rural temperature difference are investigated. A comparison between the temperature profiles from the model and those from radio soundings at Trappes (location, see Fig. 1) is shown in Fig. 4. The model profiles at this rural site have an overall negative bias of $-1.75 \mathrm{~K}$ and an mean absolute error of $1.5 \mathrm{~K}$. Yet, the model is able to reproduce the overall increase in temperature over the selected period, and correctly captures daynight differences in the observed profiles. Furthermore, the $2 \mathrm{~m}$ temperatures of two fixed ground stations and their difference, at Melun in a rural area and Paris-Montsouris near the city centre (locations, see Fig. 1), are compared between the model output and observations for the selected 5-day period (see Fig. 5). The values for the $2 \mathrm{~m}$ temperature of the model are extrapolated from the lowest vertical model layer (approximately 12.5 metre) using Monin-Obukhov surfacelayer profiles accounting for stability effects. We find a correlation of 0.97 and 0.99 , absolute errors of $1.4 \mathrm{~K}$ and $1.6 \mathrm{~K}$, and a cold bias of $-0.92 \mathrm{~K}$ and $-1.45 \mathrm{~K}$ for the urban and rural station, respectively. The overall too stable vertical temperature profiles at the rural site Trappes and negative bias 

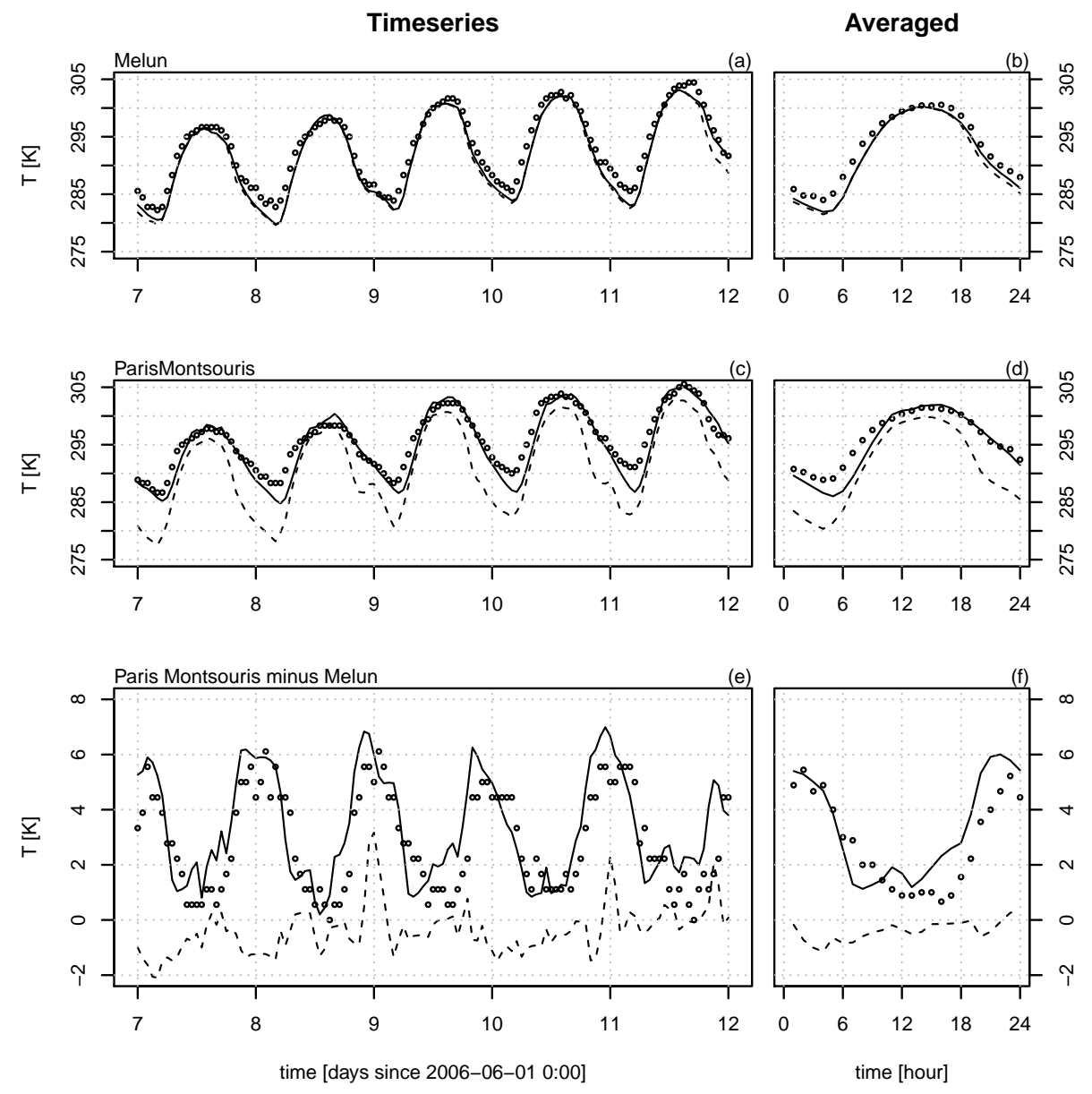

Fig. 5. The temperature time series for Melun (a), Paris-Montsouris (c), and the difference between the sites (e), for the observations (circles), base run (full line) and scenario run (dashed line), and their hourly averaged diurnal cycle (b, d, f).

in the $2 \mathrm{~m}$ temperatures mainly occur during the night. This is accompanied by wind profiles with a too strong nocturnal low-level jet. Hereby, an overestimation of the peak in wind speed could reach a factor two in some of the nocturnal profiles at Trappes. A possible reason is the uncertainty in the turbulent mixing parametrization for stable boundary-layer conditions, see e.g. Cuxart et al. (2006). Furthermore, the vertical turbulent mixing generated by low-level circulations due to topography or the urban UHI itself could be underestimated by the ARPS model. This could result in too stable nocturnal temperature profiles which further reduce the turbulent mixing. This "feedback" of reduced vertical mixing may explain the overestimation of the nocturnal low-level jet. In this respect, the effect of nocturnal stability and the lowlevel jet on the UHI build-up are addressed in Sects. 3.4.4 and 3.4.5.

The temperature difference between the two stations, which reflects the thermal contrast between the urban and rural areas, is now evaluated. The modeled and observed differences and their diurnal cycle are shown in Fig. 5. The differences have a daily mean of $2.81 \mathrm{~K}$ and $3.35 \mathrm{~K}$, respec- tively, and we find a correlation of 0.80 . The model overestimates the temperature difference with $0.54 \mathrm{~K}$ which starts to increase too early in the evening. The (nocturnal) maximum UHI intensity averaged for the five days is well captured by the model but with a slight overestimation. We find temperature differences of $6.0 \mathrm{~K}$ and $5.5 \mathrm{~K}$ for model output and observations, respectively, so it is overestimated by $0.5 \mathrm{~K}$ (or $9.1 \%$ ). Although the model has an overall negative bias during the night, the urban-scale temperature fluctuations, which includes the UHI, are well represented in the model. Furthermore, the fact that the temperature difference between the urban and rural station becomes zero in the scenario run (for which the urban surface is replaced by crops) confirms that it is caused by the urban surface heating.

\subsection{Impact of urbanization on the surface energy balance}

As a start to investigate the effect of urban surface heating on the evolution of the UHI, the surface energy balance (SEB) in the city centre is analysed. The averaged diurnal cycle over 

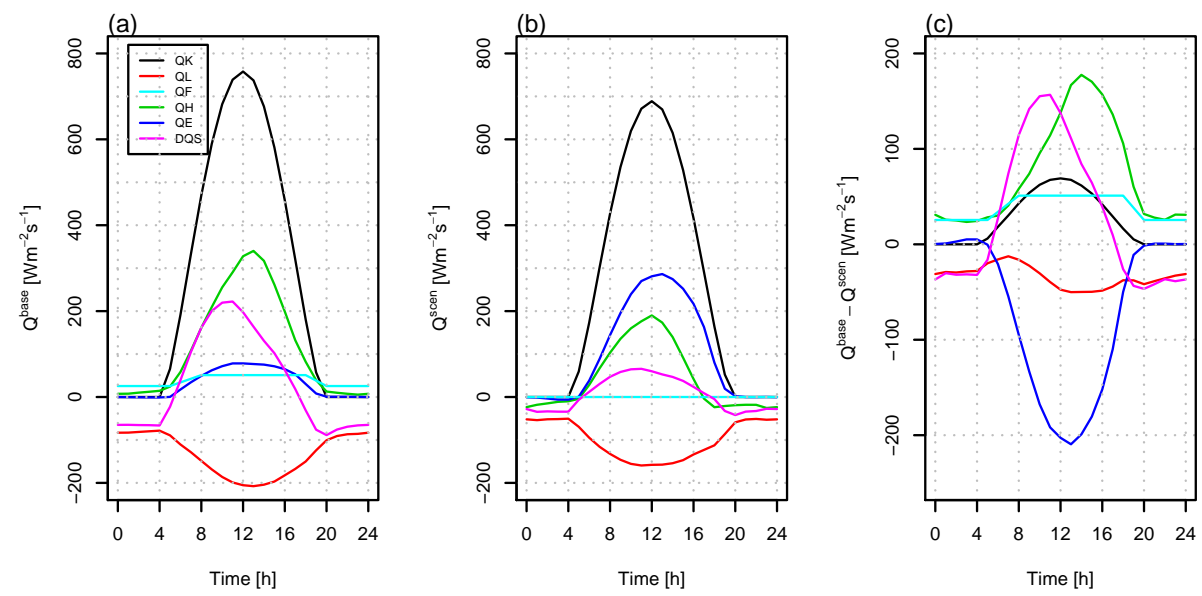

Fig. 6. The 5-day averaged diurnal cycle of the surface energy fluxes at Paris-Montsouris (city centre) for the base run (a), the scenario run (b) and their difference (c).

the selected period is considered so that short-term fluctuations are averaged out (see Fig. 6).

The surface energy balance, which is a statement of the energy conservation at the surface, can be written as

$Q^{*}+Q_{\mathrm{F}}=Q_{\mathrm{H}}+Q_{\mathrm{E}}+\Delta Q_{\mathrm{S}}$,

where $Q^{*}$ is the net all wave radiation flux density, $Q_{\mathrm{F}}$ the anthropogenic heat flux, $Q_{\mathrm{H}}$ the surface sensible heat flux, and $Q_{\mathrm{E}}$ surface latent heat flux release. The storage heat flux $\Delta Q_{\mathrm{S}}$ represents the total heat transfer to/from the urban surface/ground that includes buildings (roofs and walls) and roads, and is equivalent to the ground heat flux. Furthermore, $Q^{*}$ is composed of net short wave $\left(Q_{\mathrm{K}}\right)$ and long-wave radiation $\left(Q_{\mathrm{L}}\right)$ :

$Q^{*}=Q_{\mathrm{K}}+Q_{\mathrm{L}}=\left(K_{\downarrow}-K_{\uparrow}\right)+\left(L_{\downarrow}-L_{\uparrow}\right)$,

where $K_{\downarrow}$ and $L_{\downarrow}$ are the incoming short-wave and longwave radiation, and $K_{\uparrow}$ and $L_{\uparrow}$ the outgoing short-wave and long-wave radiation.

The surface fluxes at Paris-Montsouris are compared between the base run and scenario run. In the former, the grid cell has $85 \%$ of urban land surface. In the latter, the urban surface is replaced by vegetation in which similar surface fluxes are obtained as for the base run at the rural location at Melun.

Several source terms in the energy budget appear during the day owing to the urban surface, which is also found in earlier model studies of Van Weverberg et al. (2008); Lemonsu and Masson (2002); Lemonsu et al. (2009); Bohnenstengel et al. (2011). Hereby, the large reduction in latent heat release $\left(Q_{\mathrm{E}}^{\text {base }}-Q_{\mathrm{E}}^{\text {scen }}\right)$ dominates the increase in absorbed solar radiation ( $\left.Q_{\mathrm{K}}^{\text {base }}-Q_{\mathrm{K}}^{\text {scen }}\right)$ and the additional anthropogenic heat flux $Q_{\mathrm{F}}$. These urban source terms are balanced by an increased net outgoing long-wave radiation $\left(-\left(Q_{\mathrm{L}}^{\text {base }}-Q_{\mathrm{L}}^{\text {scen }}\right)\right)$, a storage heat flux $\Delta Q_{\mathrm{S}}^{\text {base }}-\Delta Q_{\mathrm{S}}^{\text {scen }}$ and sensible heat flux $Q_{\mathrm{H}}^{\text {base }}-Q_{\mathrm{H}}^{\text {scen }}$ in the city centre. The increased sensible heat release leads to a minor increase in the $2 \mathrm{~m}$ temperature of $2 \mathrm{~K}$ during the day (see Fig. 5).

The urban source terms at nighttime are very different to those at daytime. An nocturnal excess in storage heat $\left(\Delta Q_{\mathrm{S}}^{\text {base }}-\Delta Q_{\mathrm{S}}^{\text {scen }}\right.$ ) release which was stored during the day is the same magnitude as the anthropogenic heat flux $Q_{\mathrm{F}}$ at that time. They are balanced by an increased net outgoing long-wave radiation $\left(-\left(Q_{\mathrm{L}}^{\text {base }}-Q_{\mathrm{L}}^{\text {scen }}\right)\right)$ and sensible heat $\left(Q_{\mathrm{H}}^{\text {base }}-Q_{\mathrm{H}}^{\text {scen }}\right)$. In particular, $Q_{\mathrm{H}}^{\text {base }}$ is positive as opposed to $Q_{\mathrm{H}}^{\text {scen }}$ which is negative. It is remarkable that the impact on the $2 \mathrm{~m}$ temperature is increased further during the night, even though $Q_{\mathrm{H}}^{\text {base }}-Q_{\mathrm{H}}^{\text {scen }}$ is much smaller than during the day. It can be explained by the stable stratification during the night which retains the urban source terms much closer to the ground than the unstable stratification during the day, as mentioned in Bohnenstengel et al. (2011). The further intensification of the UHI during the night with relative small difference in surface sensible heat flux is demonstrated more precisely in Sect. 3.4.2 with the single-column Lagrangian advection model.

Note that over the urban surface, in which we are dealing with bluff-rough elements, much lower thermal roughness lengths occur in the city (Sugawara and Narita, 2008) compared to vegetative areas which reduce the turbulent transfer of heat from the surface during the day. This is in contrast to what one may expect from high roughness lengths for momentum in cities which actually tend to increase the turbulent transfer. This turbulence inhibition which blocks the surface sensible heat release during the day, together with the higher heat capacity of the urban surface with a large amount of buildings (Lemonsu and Masson, 2002; Harman and Belcher, 2006; Oleson et al., 2011), is important because it favours an increase of storage heat. The latter is released subsequently as sensible heat during the night and 

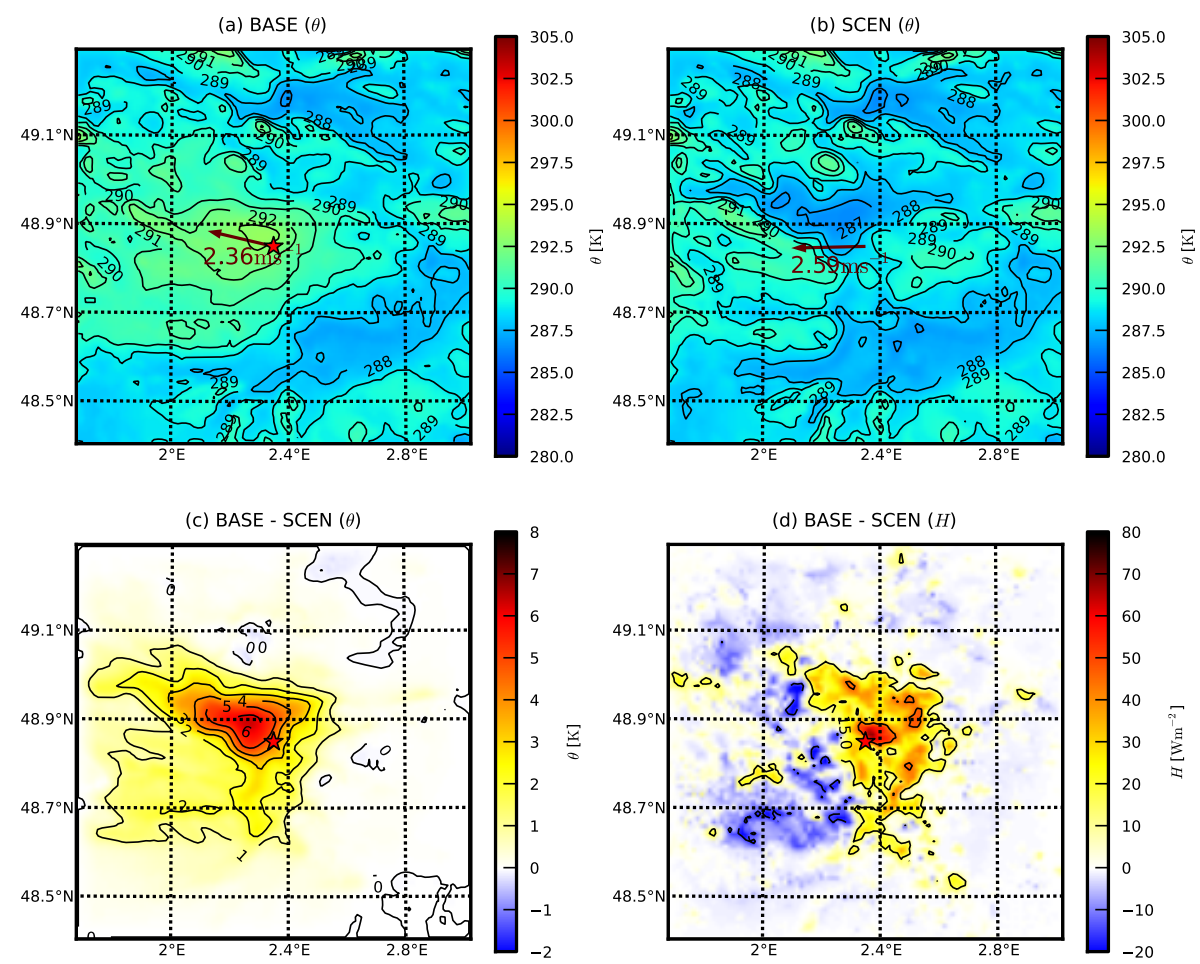

Fig. 7. The potential temperature in K over Paris at 23:00 UTC at $12.5 \mathrm{~m}$ for the base run (a), scenario run (b) and the difference (c). The difference in surface sensible heat between the base run and scenario run is given by (d). The city centre is indicated with the red star and the horizontal wind with the red arrow.

this directly influences the nocturnal temperature (profile) demonstrated in Sect. 3.4.2.

In the early morning, a decrease in temperature difference between urban and rural station is partly explained by the increased storage heat opposed to the excess sensible heat. This stems from the already mentioned large heat capacity of urban surfaces and from the heat blocking effect due to very low thermal roughness lengths for bluff-rough elements typical for urban areas. This could even lead to an urban "cool" island which can last for the whole day, as found over Oklahoma city (Lemonsu et al., 2009). Nevertheless in this case study for Paris, the excess in sensible heat release remains positive in the morning which would still suggest an increase instead of decrease in temperature difference. Yet, the UHI intensity is reduced since the excess in sensible heat and temperature is distributed by turbulent diffusion due to the development of a convective boundary layer.

To conclude, the large reduction of the latent heat release, and to a lesser extent the reduced reflected solar radiation and anthropogenic heat for urban surfaces basically explain the large increase in storage heat uptake at noon and sensible heat release in the afternoon. The latter results in a modest impact on the near-surface temperature as it is mixed over a larger depth because of unstable stratification. The heat which was stored during the day and, to a lesser extent, the added anthropogenic heat results in a small impact on the sensible heat during the night. However, this leads to a much stronger impact on the near-surface temperature compared to the day. During the night, the UHI is at its maximum as this extra heat is retained close to the ground because of stable stratification.

\subsection{The horizontal and vertical extent of the urban heat island}

The maximum UHI intensity at 23:00 UTC of $6.1 \mathrm{~K}$ is found at about $6 \mathrm{~km}$ downwind of the city centre along the wind vector (Fig. 7). This downwind shift is also found in Bohnenstengel et al. (2011). In fact, the boundary-layer UHI increases when moving over the city along the wind vector up to the location where the excess in sensible heat release induced by the urban surface vanishes. The extent of the UHI has approximately the same horizontal size as the total area of the suburban and urban terrain of Paris. The UHI intensity is much lower during the day (Fig. 8), even though the magnitude and extent of the differential sensible heat flux is much larger than during the night. The downwind shift of the UHI intensity is negligible in the results for the day.

During the day between 09:00 UTC and 18:00 UTC, the large excess in sensible heat is found (see Sect. 3.2). This is distributed over large depth of the convective boundary layer during the day (Fig. 9). This vertical distribution limits the UHI intensity to at most $2.5 \mathrm{~K}$ near the surface, but a small 

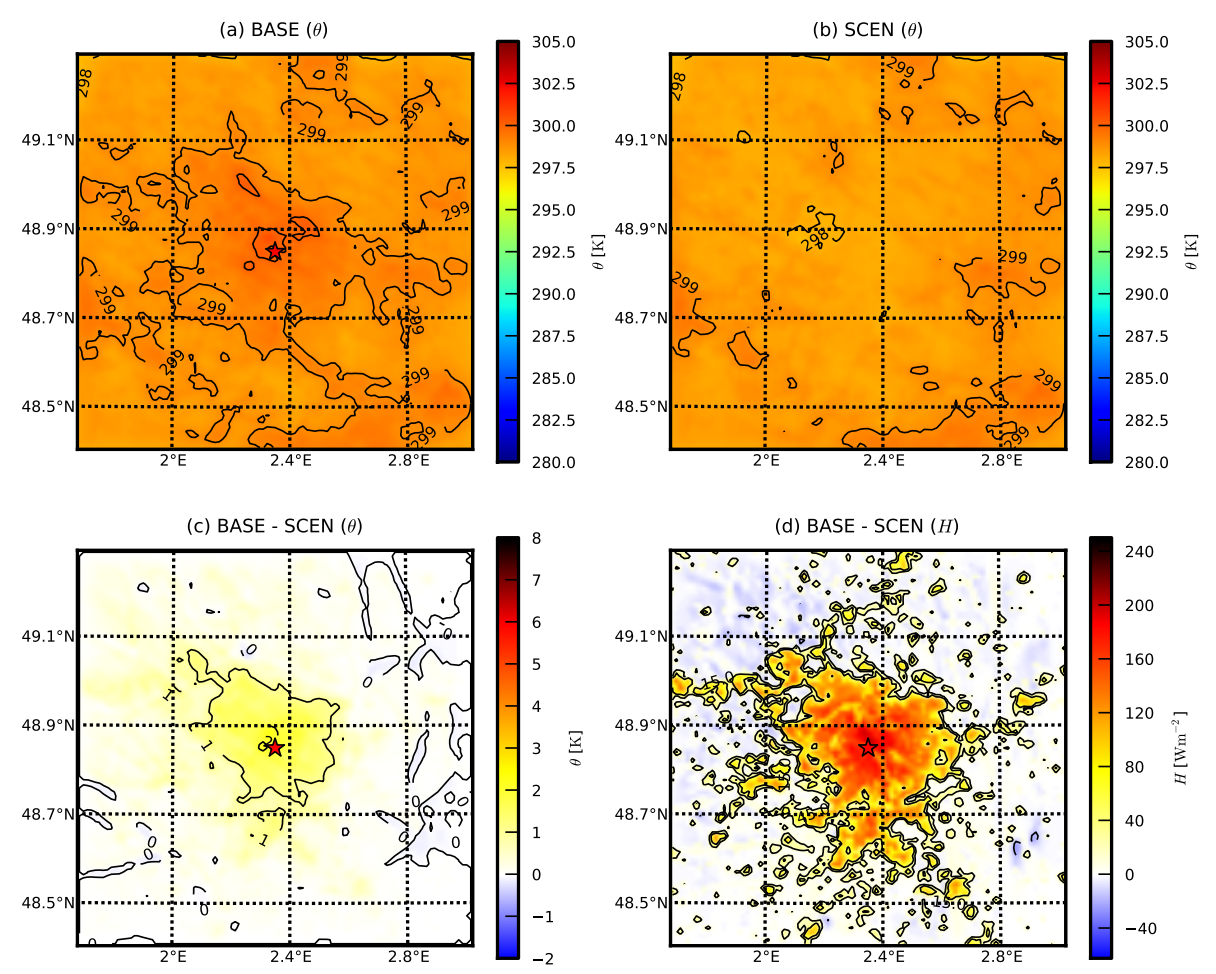

Fig. 8. The same as in Fig. 7, but for 15:00 UTC.

impact on the vertical temperature of $0.5 \mathrm{~K}$ is still found up to the mixing height of $800 \mathrm{~m}$. During the night, a positive instead of negative $Q_{\mathrm{H}}^{\text {base }}$ is found. As a consequence, a neutral mixed layer with a small depth is formed over the city, while the temperature profile becomes stable over cropland. The UHI intensity increases up to $6.1 \mathrm{~K}$ at 23:00 UTC $6 \mathrm{~km}$ downwind of the city centre with a decreasing lapse rate of $0.05 \mathrm{~K} \mathrm{~m}^{-1}$ (Fig. 10). The UHI intensity is confined to $150 \mathrm{~m}$ depth under nocturnal boundary-layer conditions, hence the large impact of a relative small excess in sensible heat. This is discussed hereafter with the idealized advection approach. The differential surface sensible heat remains positive for the entire night under nocturnal stability. Therefore, the UHI persists with only a slight decrease until the morning (06:00 UTC) when a convective boundary layer with a large depth is formed. Note that a small cooling of about $-0.5 \mathrm{~K}$ occurs at $200-400 \mathrm{~m}$ above the city. This can be ascribed to the cross-over effect (Cermak et al., 1995; Oke, 1982): entrainment occurs at the elevated inversion base above the city due to roughness and buoyancy effects. This cross-over effect might then correspond to the layer from which heat has been removed by entrainment.

\subsection{Contributions and impacts on the nocturnal UHI build-up with the advection model}

\subsubsection{Advection model set-up}

The advection model is applied for both scenarios between 22:00 UTC and 23:00 UTC starting $6 \mathrm{~km}$ upwind of the city centre traveling a distance of $12.6 \mathrm{~km}$ over Paris, see Fig. 11. The meteorological conditions as input for the advection model are adopted from the ARPS model output averaged for the 5-day period between 22:00 and 23:00 UTC for the respective scenarios. Hereby, the advection model accounts for the synoptic east wind of $3.5 \mathrm{~m} \mathrm{~s}^{-1}$. For the base case which includes the urban surface, a constant sensible heat sink of $-10 \mathrm{~W} \mathrm{~m}^{-2}$ is considered for the first $12 \mathrm{~min}$ (NBL) and a heat source of $15 \mathrm{~W} \mathrm{~m}^{-2}$ during the 48 subsequent minutes (CBL). For the scenario case (hereafter scen case) for which urban surface is replaced by cropland, a surface sensible heat sink of $-20 \mathrm{~W} \mathrm{~m}^{-2}$ is prescribed for the entire hour (NBL). Idealized piecewise linear profiles need to be considered for the initial state of the advection model. The profile of the lowest $150 \mathrm{~m}$ is fitted with linear regression from the ARPS model results at 22:00 UTC $6 \mathrm{~km}$ upwind (east) of the city centre for both scenarios (Fig. 12a). Hereby, profile slopes of $0.26 \mathrm{~K} \mathrm{~km}^{-1}$ and $0.58 \mathrm{~K} \mathrm{~km}^{-1}$ were found for the base and scen case, respectively. The temperature at the inversion height was calculated from the average between 150 and $400 \mathrm{~m}$ above ground level. Note that the profile of the 

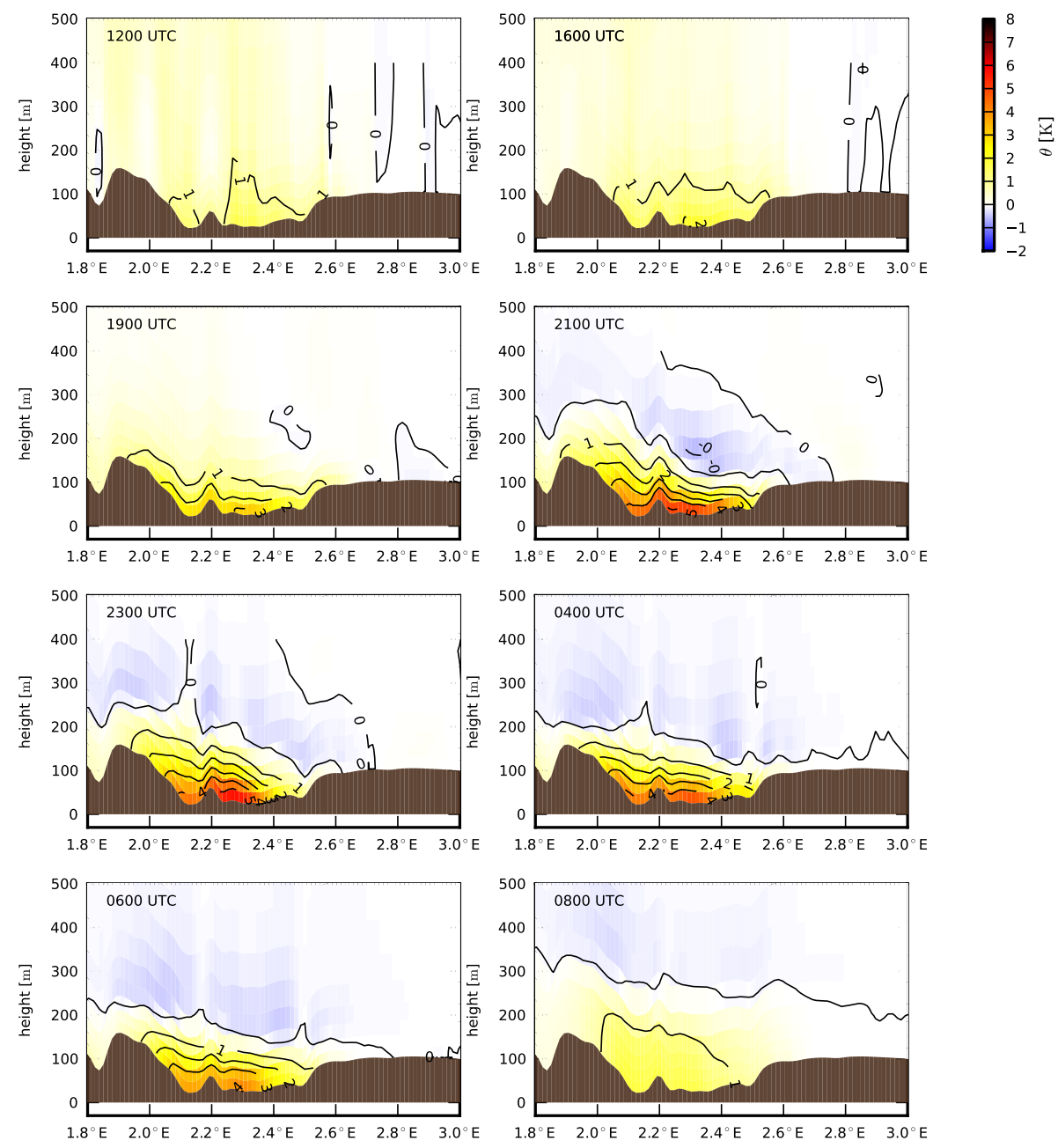

Fig. 9. 5-day averaged diurnal cycle run through Paris along the wind direction. The city centre is indicated with a red star.

base case is already somewhat destabilized because of the less negative surface sensible heat compared to the scenario case before 22:00 UTC.

We consider a upward wind relative to the surface topography of $0.012 \mathrm{~ms}^{-1}$, which appears over a considerable part of the city in the ARPS output. As demonstrated in Appendix A, this is established by the flow over the ramp east of the city centre due to the synoptic east wind. Hereby, the order of magnitude of this vertical uplift relative to the surface can be reproduced theoretically by considering a stratified flow over an idealized ramp in which the acceleration occurs at the downward slope east of the city centre. Note that the radiative cooling is neglected in the CBL and NBL models. This is discussed in Sect. 3.4.6.

\subsubsection{Advection model results}

The idealized CBL and NBL advection models are compared with the ARPS model output for the base case and scen case. They could reproduce the evolution of the temperature pro- file for the lowest $150 \mathrm{~m}$ very well for an air column moving with the wind in the respective scenarios (Fig. 12b). They clearly demonstrate that the nocturnal surface sensible heat flux and vertical ramp uplift (indicated with LIFT) are the processes dominating the changes in the respective temperature profiles. These processes also explain the increase in UHI intensity between 22:00 UTC and 23:00 UTC and the UHI maximum of $6.1 \mathrm{~K}$, even though the nocturnal difference in surface sensible heat between the two scenarios is much smaller than during daytime. This UHI build-up was about the same as from the ARPS model results.

In the base case with the city of Paris, a mixed layer is formed up to a height $h_{e}$ of $80 \mathrm{~m}$ due to surface heating, and a stable layer remains aloft. In the scen case where the city of Paris is replaced by cropland, a stable profile persists which is cooled efficiently in the vertical up to the inversion height $h_{i}$ due to a constant surface cooling, but also due to the vertical advection of potential temperature. The latter process is explained in more detail in the next subsection. Meanwhile, the inversion height is displaced in the upward direction. 

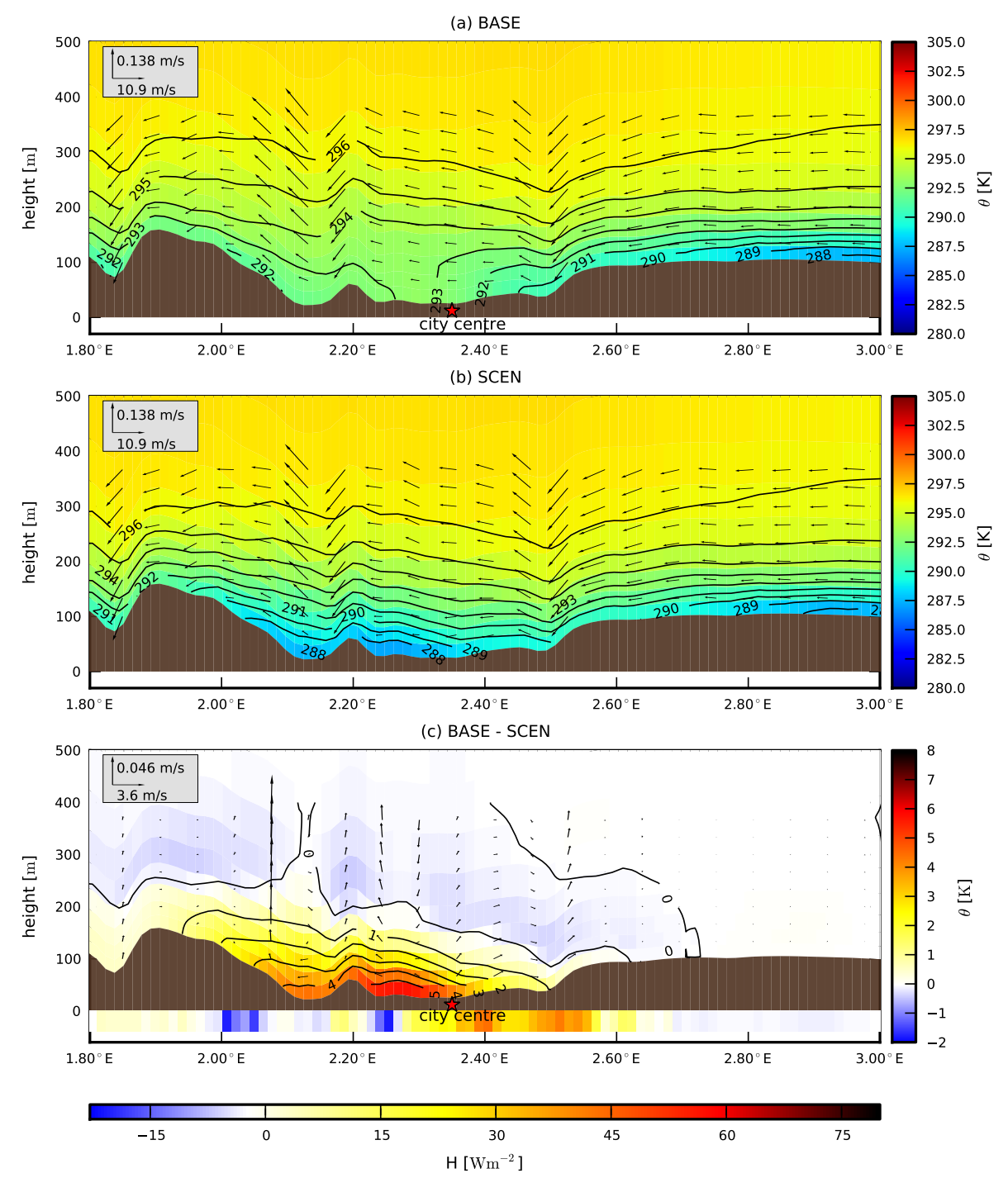

Fig. 10. 5-day averaged vertical profiles of potential temperature over Paris at 23:00 UTC for the base run (a), scenario run (b) and their difference (c). The differential surface heat flux is added to the bottom of (c).

\subsubsection{Impact of adiabatic cooling due to vertical motion}

As mentioned in Sect. , the synoptic east wind results in an uplift relative to the surface caused by the ramp upwind of the city centre. As the wind speed and direction changes depending on the synoptic situation, this topographic effect does not always take place. For example, weak synoptic pressure gradients would lead to a downslope wind from the west just parallel to the surface. In this respect, the impact of this vertical motion induced by orography on the vertical temperature profile over both the city and cropland is now studied. Therefore, two additional runs with the idealized advection model (indicated with NLFT) are performed which now exclude the upward motion $\left(w_{h}=0\right)$.

In the base case, the effect of neglecting the uplift on the near-surface temperature is small $(0.57 \mathrm{~K})$, but the layer be- tween $50 \mathrm{~m}$ and $200 \mathrm{~m}$ is now significantly warmer because of the absence of vertical adiabatic cooling. The mixed-layer height is also reduced from $80 \mathrm{~m}$ to $55 \mathrm{~m}$. In contrast, the effect of the uplift on the near-surface temperature is much greater in the scen case $(2.03 \mathrm{~K})$ where the city of Paris is replaced by cropland. It even turns out that in the scenario run, the cooling and increase in inversion height because of vertical heat advection is much greater than from the surface cooling alone. The reduced sensitivity of the near-surface temperature to the uplift in the base case compared to the scen case results from the formation of a small mixed layer in response to positive sensible heat flux over the city. In this mixed layer where the potential temperature is constant, the vertical temperature advection becomes zero even though there is vertical motion. Only a slight reduction in the mixed-layer temperature appears because the sensible heat is mixed over a slightly 

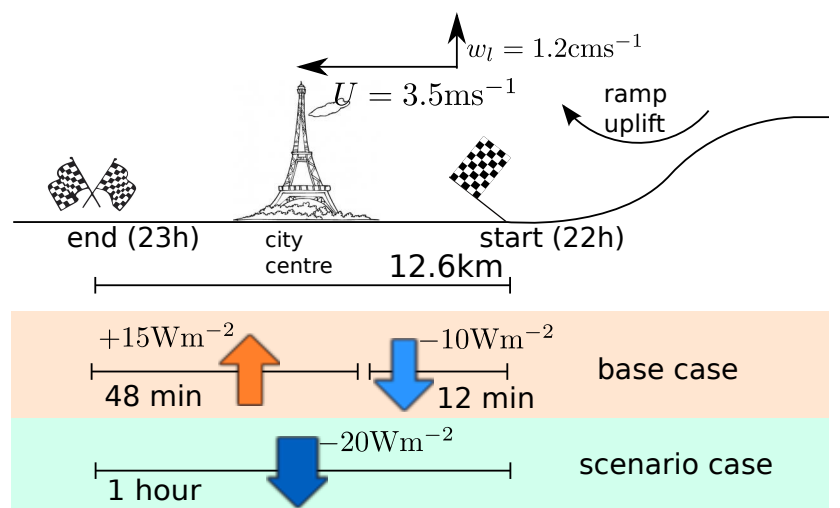

Fig. 11. Overview of the idealized advection model set-up over Paris for the base case and the scenario case. Surface sensible heat fluxes, horizontal and vertical wind speed and duration of simulation are shown.
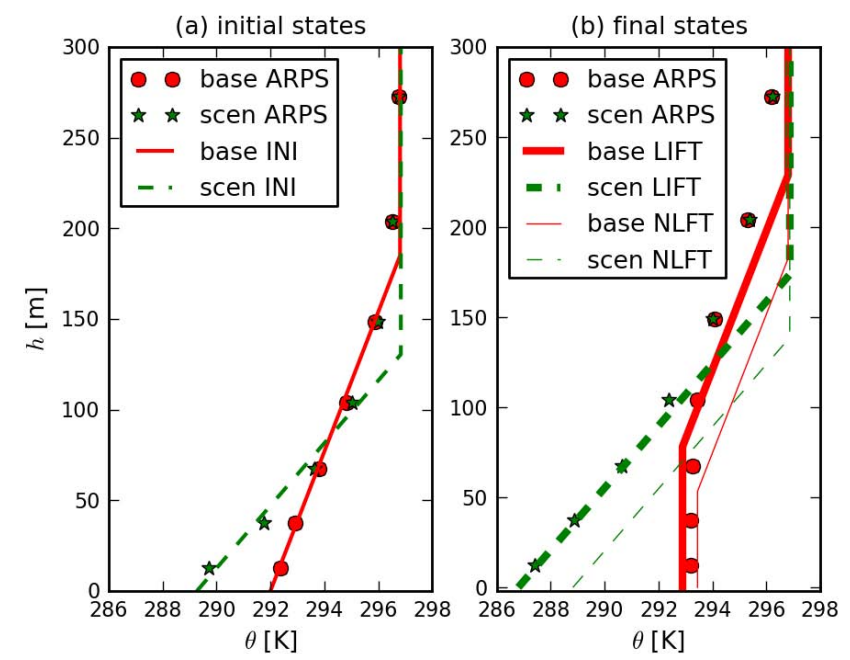

Fig. 12. Vertical potential temperature profiles from ARPS and from idealized boundary-layer advection models. $h$ indicates the height above ground level. The initial (22:00 UTC, $6.3 \mathrm{~km}$ upwind) and final states (23:00 UTC, $6.3 \mathrm{~km}$ downwind) are plotted on (a) and (b), respectively. In both panels, the profiles from the ARPS output are indicated with red circles and green stars for the base run and scenario run, respectively. The full red line in (a) represents the fitted initial state for the idealized advection models for the base case (base INI), and the dashed green line that for the scenario case (scen INI). In (b), thick lines are referring to the final states of the idealized models with orographic uplift (LIFT), and thin lines without orographic uplift (NLFT) for the respective scenarios.

increased mixed-layer height due to the uplift. For the base case, the largest sensitivity to vertical temperature advection is not close to the surface, but only in the layer between 50 to $200 \mathrm{~m}$ where the potential temperature is not constant and adiabatic cooling is important. For the scen case, the impact of the adiabatic cooling is large for the entire NBL up to the inversion height.
Excluding the upward motion, the differential surface heating between the base case and scen case between 22:00 UTC and 23:00 UTC results in an UHI build-up from $2.7 \mathrm{~K}$ to $4.6 \mathrm{~K}$ at the surface (compare 'base NLFT' with "scen NLFT" in Fig. 12b). This UHI build-up is smaller than for the simulations including the vertical motion $(6.1 \mathrm{~K})$. It can be explained by the difference adiabatic cooling at the surface between the base case and the scen case explained above. Hence, an additional UHI build-up at the surface of $1.5 \mathrm{~K}$ is explained by the decrease in adiabatic cooling over the city compared that over cropland. This amounts to $25 \%$ of the total UHI intensity. Because of the distinct impact of vertical motion on the vertical temperature profile over the city (base case) and over cropland (scen case) explained in the previous paragraph, the whole vertical extent of the UHI is affected by the ramp uplift as well.

Note that the adiabatic cooling due to orographic forcing only exists for the nocturnal situation, and does not affect the near-surface temperature or UHI intensity during the day. Indeed, the near-surface potential temperature for the scenario run (Fig. 7b) resembles the orography around Paris (Fig. 1), which is not the case in the scenario run for the day (Fig. 8). It stems from the fact that during the day, it is dealt with a CBL in both scenarios for which the (change in) vertical heat advection is negligible as mentioned above, especially when the mixed-layer height is very high.

\subsubsection{Sensitivity to the nocturnal stability}

As mentioned in the evaluation, the ARPS-model tends to produce too stable surface-temperature profiles. Therefore, the impact of nocturnal stability on the UHI build-up is discussed. This is done by dividing the slopes of initial temperature profiles at 22:00 UTC by a factor 2, see Fig. 13 . The cases excluding the uplift are considered first. On the one hand, the change in the near-surface temperature for the base case along the trajectory is decreased by $0.4 \mathrm{~K}$, because the positive heat flux gets distributed over a deeper mixed layer. On the other hand, the near-surface temperature change remains about the same for the scen case (at least if one considers the same inversion height). Therefore, a decrease in nocturnal stability results in a decrease in UHI build-up when the uplift is excluded. Furthermore, if one includes the uplift, the adiabatic cooling is decreased by $1.0 \mathrm{~K}$ for the scen case while the lower adiabatic cooling in the base case is only decreased by $0.2 \mathrm{~K}$ (compare difference in thick and thin dashed lines between Figs. 12 and 13 for the final states). As a result, the overall reduced adiabatic cooling due to destabilization results in an additional decrease of the overall UHI intensity of $0.8 \mathrm{~K}$ as well. Hence, the decrease in stability by a factor two leads to a total decrease of the UHI buildup of $0.8 \mathrm{~K}+0.4 \mathrm{~K}=1.2 \mathrm{~K}$ ( $20 \%$ of the overall UHI intensity). Therefore, the too stable boundary temperature profiles found at natural land-covers in the ARPS model may explain its overestimation of the UHI build-up. 

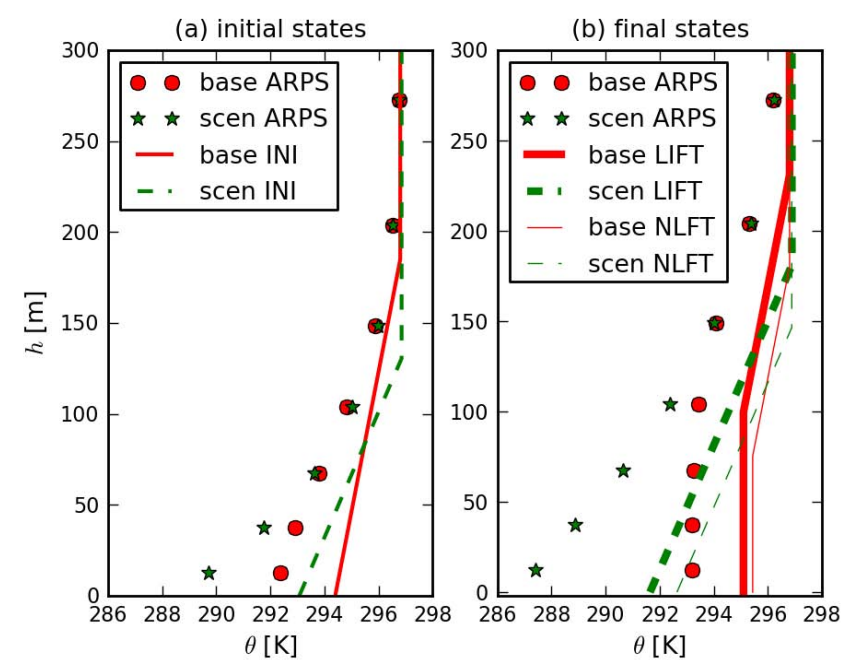

Fig. 13. The same as in Fig. 12, except that the stability of the initial profiles for the base and scen case are now reduced by a factor two.

\subsubsection{Sensitivity to the nocturnal low-level jet}

The ARPS model tends to reproduce a too strong nocturnal low-level jet. In this respect, the effect of a reduction of the nocturnal low-level jet is now explained with the idealized advection model. Hereby, it is assumed that the near-surface horizontal wind speed below is reduced by the same factor as the nocturnal low-level jet aloft, see Fig. 14. On the one hand without considering the vertical uplift, such a decrease results in an increase of the UHI build-up: when halving the wind speed $\left(1.75 \mathrm{~ms}^{-1}\right.$ instead of $\left.3.5 \mathrm{~ms}^{-1}\right)$, the air-column would need twice as much time for the trajectory under consideration, so two hours instead of one hour. For the CBL in the base case without upward motion and starting from a zero mixed-layer depth $\left(h_{e}=0\right)$, it can be derived from Eqs. (3) and (4) that the increase in surface temperature (now $2.05 \mathrm{~K}$ instead of 1.45 ) along the trajectory reduces by the square root of this time factor two. Analogously for the NBL in the scen case starting from a inversion height of $150 \mathrm{~m}$, one can show with a Taylor expansion that the decrease in temperature (now -0.90 instead of $-0.45 \mathrm{~K}$ ) is enhanced by the time factor itself. This means that without upward motion the UHI-build-up over the trajectory increases from $1.90 \mathrm{~K}$ to $2.95 \mathrm{~K}$ due to a decrease in horizontal wind speed. As a result, the UHI-intensity would reach a value of $5.65 \mathrm{~K}$ instead of $4.60 \mathrm{~K}$ (considering the same initial value at the starting point of $2.72 \mathrm{~K}$ ). On the other hand, the vertical uplift tends to decrease by a factor two as well (cfr. Eq. A6). This means that the rate of strong adiabatic cooling at the surface due to vertical advection, which mostly occurs over cropland in the scen case, is reduced. Consequently, the overall UHI build-up is now reduced. This is partially counteracted by the fact that the air column now takes twice as much time over the same trajectory. Accounting for these opposing effects, the overall adiabatic cooling in the base case becomes slightly larger
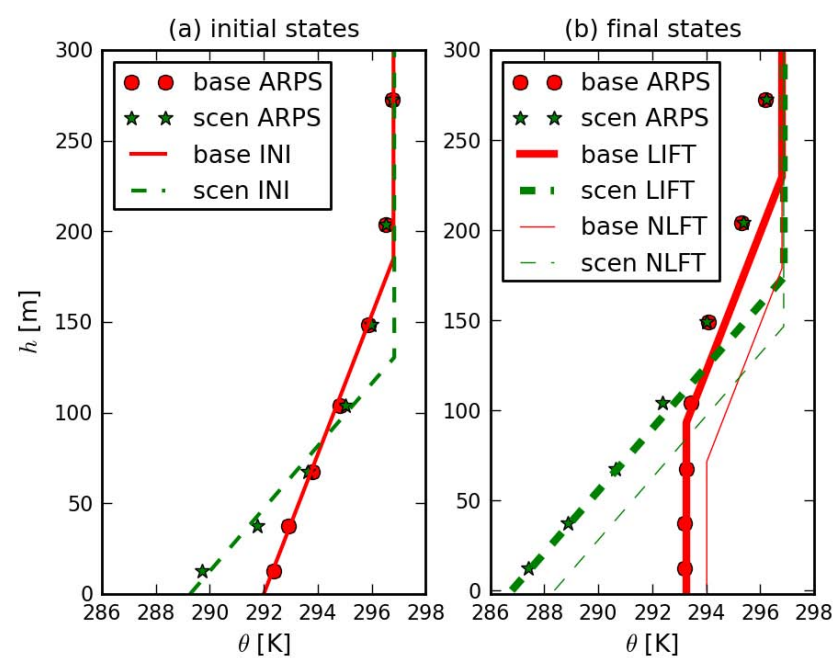

Fig. 14. The same as in Fig. 12.The horizontal and vertical wind speed for both scenarios are reduced is by a factor two in the advection model. The final states of the advection model represents the temperature profile for 00:00 UTC at $6.3 \mathrm{~km}$ downwind of the city centre, because the time over the trajectory of $12.6 \mathrm{~km}$ is increased by a factor two. These are compared with the ARPS profiles for 23:00 UTC at the same position.

$(-0.76 \mathrm{~K}$ instead of $-0.57 \mathrm{~K})$, whereas for the scen case, it becomes smaller $(-1.58$ instead of $-2.03 \mathrm{~K})$. As a result, the impact of a reduced horizontal wind speed on the reduction of the adiabatic cooling (base minus scen) is $-0.64 \mathrm{~K}$, so contributes negatively to the overall UHI build-up. In summary, an overestimation of the nocturnal jet could lead to an underestimation of UHI build-up. In the absence of the ramp uplift, the underestimation becomes larger.

\subsubsection{Impact of radiative cooling}

The impact of this radiative cooling on the UHI build-up is discussed. This was excluded in the idealized advection model. Therefore, the radiative cooling to ground and space in the boundary layer is estimated from the boundary-layer temperature profiles and surface temperatures from ARPS during the trajectory. For the scen case, the difference between the surface temperature $\left(T_{\mathrm{S}}=281 \mathrm{~K}\right)$ and screen-level temperature $\left(T_{2 \mathrm{~m}}=284 \mathrm{~K}\right)$ amounts to $3 \mathrm{~K}$ over the trajectory between 22:00 and 23:00 UTC in the ARPS results. Applying Eq. (8.41) from Pielke (2002) and using a mixing ratio of $q=7.5 \mathrm{~g} \mathrm{~kg}^{-1}$ from the ARPS model output, this leads to a radiative cooling to space for the first $150 \mathrm{~m}$ above the surface lower than $-0.03 \mathrm{~K} \mathrm{~h}^{-1}$ for both scenarios, so this was neglected. In contrast, the radiative cooling rate to the ground for a thin layer of four metres above the surface at the screenlevel temperature $\left(T_{2 \mathrm{~m}}=284 \mathrm{~K}\right)$ amounts to $-1.76 \mathrm{~K} \mathrm{~h}^{-1}$. However, the large radiative cooling is limited to a thin layer above the surface that could lead to a negative curvature of the temperature profile found in ARPS. Even more extreme 
cooling rates were found in Steeneveld et al. (2010) between $1.3 \mathrm{~m}$ and $10 \mathrm{~m}$ above the surface of up to $-3.5 \mathrm{~K} \mathrm{~h}^{-1}$ for very stable conditions. Hereby, one should note that the idealized advection model only accounts for a piecewise linear vertical temperature profile in which cooling rates are constant over the CBL or NBL. Therefore, one cannot capture the extra radiative cooling near the surface. This cooling near the surface could be partially counteracted by a possible redistribution of the vertical temperature profile by turbulent mixing. Furthermore, the radiative cooling of the next $150 \mathrm{~m}$ (above this thin layer) is much smaller $\left(-0.29 \mathrm{~K} \mathrm{~h}^{-1}\right)$ than for this thin layer. Hereby, a constant temperature of $T=293 \mathrm{~K}$ representative for the top of the NBL is considered, so this cooling rate can be considered as a (negative) upper limit. Both Savijärvi (2006) and Ha and Mahrt (2003) find radiative cooling rates no lower than $-0.5 \mathrm{~K} \mathrm{~h}^{-1}$ with similar nocturnal situations, except for a thin layer close to the ground. Yet, this cooling rate of the NBL is of the same order as the cooling due to the negative surface sensible heat flux of $-0.45 \mathrm{~K} \mathrm{~h}^{-1}$ (scen case NLFT minus INI), but lower than the adiabatic cooling for the scen case of $2 \mathrm{Kh}^{-1}$ (scen case LIFT minus NLFT).

For the base case, one finds surface temperatures of $T_{\mathrm{S}}=290 \mathrm{~K}$, screen-level temperatures of $T_{2 \mathrm{~m}}=291 \mathrm{~K}$ and mixed-layer temperatures of $295 \mathrm{~K}$. On the one hand, the cooling rate of a four-metre thin layer above the surface amounts to $0.63 \mathrm{~K} \mathrm{~h}^{-1}$, which is lower than the radiative cooling rate of $-1.76 \mathrm{~K} \mathrm{~h}^{-1}$ in the scen case. This differential cooling rate may lead to an extra heat-island build-up of $1.1 \mathrm{~K} \mathrm{~h}^{-1}$ but only for a $4 \mathrm{~m}$ thin layer close to the surface ignoring a possible vertical redistribution of the vertical temperature profile. On the other hand, the cooling rate of the neutral layer of $80 \mathrm{~m}$ above this thin layer is $-0.12 \mathrm{Kh}^{-1}$. As a result, the differential radiative cooling between the scenarios could only slightly enhance the UHI build-up by $0.17 \mathrm{~K} \mathrm{~h}^{-1}$. This is much smaller than the UHI build-up due to the differential surface sensible heat of $1.9 \mathrm{~K} \mathrm{~h}^{-1}$ or the differential reduction in adiabatic cooling of $1.5 \mathrm{~K} \mathrm{~h}^{-1}$.

\section{Conclusions}

Using a mesoscale meteorological model at a horizontal resolution of $1 \mathrm{~km}$ and covering an area of $100 \mathrm{~km} \times 100 \mathrm{~km}$, the urban heat island over Paris during summer 2006 is studied. A base run is performed in which the present-day (urban) surface characteristics are represented, and an additional scenario run in which the urban surface is replaced by cropland. A 5-day period is analysed for which the (boundary-layer) UHI intensity is high. Even though the urban parametrization is not sophisticated, the UHI intensity is simulated very well. In particular, the maximum difference in $2 \mathrm{~m}$ temperature between urban and rural areas stemming from the urban heating is reproduced with a relative error of less than $10 \%$.
The dominant heating terms and their relative importance for the development of the maximum UHI intensity occurring during the night are analysed. The interactions between the urban surface heating, boundary-layer stability, and orography were investigated. It was found that the increased storage-heat uptake during the day, which is subsequently released during the night, is the most important reason for the difference in surface sensible heat during the night. The increased storage heat uptake stems from the reduced evapotranspiration in the city, the large heat capacity and the very small thermal roughness lengths of the urban surface. The nocturnal anthropogenic heat release is also important for the differential surface sensible heat.

The spatial extent of the maximum UHI intensity averaged over the selected 5-day period is described. Its maximum occurs at 23:00 UTC. Because the differential surface sensible heat between urban and vegetative areas remains constant under nocturnal stability, the urban heat island persists with only a slight decrease until 06:00 UTC in the morning when a large convective boundary layer is formed. The maximum UHI intensity has approximately an ellipsoidal shape stretched along the prevailing wind vector with its maximum $2 \mathrm{~m}$ temperature excess of $6.1 \mathrm{~K}$ located $6 \mathrm{~km}$ downwind of the city centre.

Even though the nocturnal differential urban sensible heat is much lower than during the day, the UHI intensity reaches its maximum during the night. In order to investigate this behaviour in a rigorous way, idealized advection models for the NBL and CBL are developed which account for the prevailing wind, turbulent surface heating/cooling and vertical uplift. Hereby, the nocturnal evolution of the temperature profile was well reproduced for both scenarios implying that vertical and horizontal advection and the exchange of sensible heat between the surface and the overlying atmosphere are the dominant processes explaining the boundary-layer structure both in the city and over cropland. It was demonstrated that the main part of the UHI build-up is directly related to the small differential surface sensible heat flux during the night. Despite this low differential sensible heat compared to the day, the UHI intensity reaches a maximum because of its confinement to the lowest $150 \mathrm{~m}$ under nocturnal stability. Hereby, the slightly positive sensible heat over the city at night results in a mixed layer of $50 \mathrm{~m}$, instead of a downward sensible heat flux of $20 \mathrm{~W} \mathrm{~m}^{-2}$ over the croplands for which the boundary layer remains stable. This implies that any further increase in urban surface heating (such as anthropogenic heat from e.g. air conditioning) during the night would likely have a larger impact on the near-surface temperature, and thus impact on human health, than a similar heat increase during the day.

An air uplift is explained by the synoptic east wind and a ramp upwind of the city centre. This induces a strong vertical adiabatic cooling over cropland for the nocturnal boundary layer. The adiabatic cooling is decreased in the case of the mixed layer over the city. This reduction could explain 


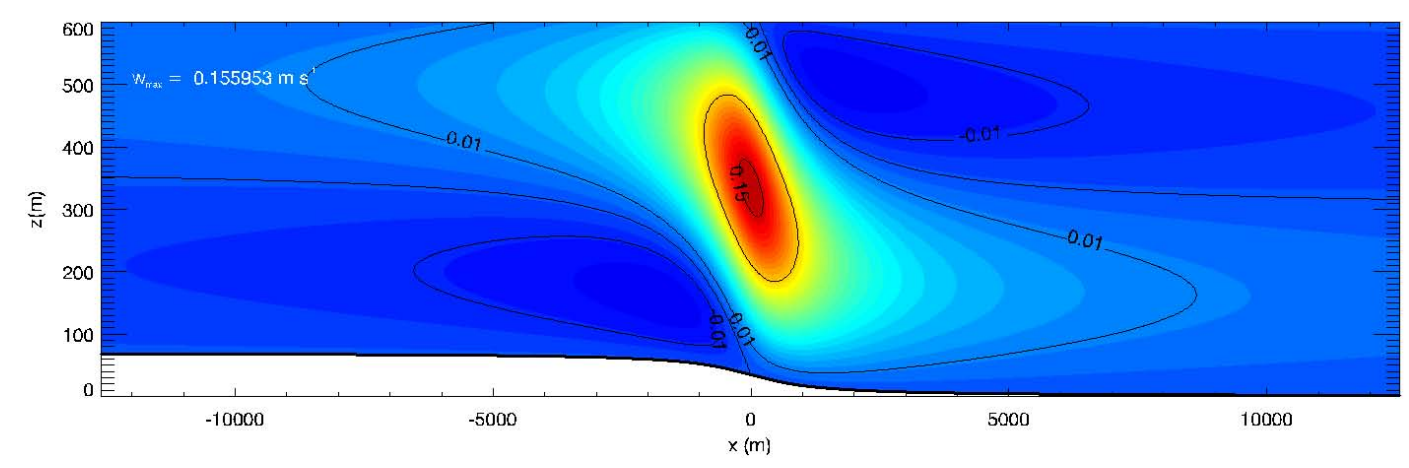

Fig. A1. Vertical velocity relative to the slope-following wind induced by a ramp in a stably stratified flow for a vertical atmospheric slice.

an important part $(25 \%)$ of the maximum UHI intensity. The differential adiabatic cooling has an impact on the vertical extent of the UHI as well. Furthermore, the UHI is affected by the nocturnal stability and the nocturnal low-level jet. Therefore, excessive nocturnal stability found in ARPS may lead to an overestimation of the UHI build-up, whereas a too strong low-level jet may result in an underestimation. The reduction of the radiative cooling to the surface due to the mixed layer above the city compared to the NBL over cropland may enhance the UHI build-up as well, but only for a few metres above the surface. From this idealized study it can be concluded that, not only the nocturnal urban surface heating itself, but also its interactions with orographic forcing, shear mixing, boundary-layer stability, the low-level jet and boundary-layer radiation determine the evolution of the whole vertical profile of the UHI. Therefore, improvements of representing these boundary-layer features in atmospheric models are important for UHI studies.

\section{Appendix A}

\section{Orographic flow over a ramp}

As apparent from Sect. 3.4.2, the vertical uplift plays an important role in explaining the evolution of the nocturnal temperature profiles, both for the base case as the scenario simulation. ARPS simulation results clearly show uplift over the city at the western (downwind) side of a ramp located at approx. $2.55^{\circ}$ E. Here, we try to verify whether this orographic feature (i.e, the ramp) is capable of explaining the simulated (in ARPS) vertical wind field relative to the slope wind, which is characterized by wind speed values of the order of a few $\mathrm{cm} \mathrm{s}^{-1}$.

We calculate the flow field induced by a ramp (Fig. A1) for a stably stratified atmosphere characterized by a lapse rate and a (constant) wind speed $U$, following Lin (2007), to do so. We assume that the stable stratification extends to infinity in the vertical direction, which is obviously a gross simplification compared to the actual situation (cfr. ARPS result), in which a stably stratified inversion layer is located underneath a residual neutral layer. We describe the orography of the ramp with height $h_{m}$ and horizontal scale $a$ as

$h_{m}(x)=\frac{1}{2} \bar{h}_{m}\left[1-\frac{2}{\pi} \arctan \frac{x}{a}\right]$.

This functional form has the advantage of having a derivative that can be easily Fourier-transformed (see below).

As in Lin (2007), we obtain the perturbation vertical velocity $w^{\prime}(x, z)$ by solving the Scorer equation for its Fouriertransform $\hat{w}(k, z)$,

$\frac{\partial^{2} \hat{w}}{\partial z^{2}}+k^{2}-l^{2} \hat{w}=0$,

with $k$ the horizontal wavenumber, and $l=N / U$ the vertical wave number, with $N=\sqrt{g \gamma / \theta_{0}}$ the Brunt-Väisäla frequency, $g$ the gravitational acceleration and $\theta \simeq 300 \mathrm{~K}$ a reference temperature.

The lower boundary condition on the vertical velocity is given by

$w^{\prime}(x, 0)=U \frac{d h_{m}}{d x}=-\frac{U \bar{h}_{m}}{\pi} \frac{a}{a^{2}+x^{2}}$

and its Fourier transform is

$\hat{w}(k, 0)=\frac{1}{2 \pi} \int_{-\infty}^{+\infty} w^{\prime}(x, 0) e^{-i k x} d x=-\frac{U \bar{h}_{m}}{2 \pi} e^{-k a}$

with the requirement that $k>0$.

The vertical velocity is then obtained by applying the inverse one-sided Fourier transform,

$$
\begin{aligned}
w^{\prime}(x, z) & =2 \Re\left\{\int_{0}^{\infty} \hat{w}(k, 0) e^{i k x} d k\right\} \\
& =-\frac{U h_{m}}{\pi} \frac{a \cos (l z)-x \sin (l z)}{a^{2}+x^{2}} .
\end{aligned}
$$

However, as we are interested in an ABL slab that follows the terrain, the terrain-following vertical velocity $w^{\prime}(x, 0)$ has to be substracted, so that finally

$w^{\prime}(x, z)=-\frac{U \bar{h}_{m}}{\pi} \frac{a \cos (l z)-1-x \sin (l z)}{a^{2}+x^{2}}$, 
which is shown in Fig. A1 for $U=3.5 \mathrm{~m} \mathrm{~s}^{-1}, a=1000 \mathrm{~m}$, $\gamma=0.04 \mathrm{~K} \mathrm{~m}^{-1}, h_{m}=70 \mathrm{~m}$, and $\theta_{0}=300 \mathrm{~K}$.

From this, it appears that, despite the simplifications, our simple orographic model is capable of reproducing the order of magnitude of the vertical wind speed.

\section{Appendix B}

\section{Solution of Eq. (3)}

In this appendix we seek a solution for

$$
\frac{\mathrm{d} h_{e}}{\mathrm{~d} t}=\frac{\overline{w^{\prime} \theta^{\prime}}}{\gamma h_{e}}+w_{h}
$$

Subject to the initial condition $h_{e}(0)=h_{0}$.

Performing a change of variable $h_{e} \equiv p^{-1}$, this equation converts into a somewhat more manageable form, which can be integrated to yield, at time $t$,

$$
\frac{\overline{w^{\prime} \theta^{\prime}}}{\gamma w_{h}^{2}} \ln \left[\frac{\overline{w^{\prime} \theta^{\prime}} \gamma^{-1}+w_{h} h_{0}}{\overline{w^{\prime} \theta^{\prime}} \gamma^{-1}+w_{h} h_{e} t}\right]+\frac{h_{e} t-h_{0}}{w_{h}}-t=0
$$

This is a transcendental equation in $h_{e}(t)$, which can be solved to any desired accuracy by mean of, e.g. the NewtonRaphson iterative zero-finding algorithm. In the case of $w_{h}=$ 0, Eq. (B2) cannot be applied, but the solution of Eq. (B1) is then trivial, and given by:

$h_{e}(t)=\sqrt{h_{0}^{2}+\overline{w^{\prime} \theta^{\prime}} \gamma^{-1} t}$.

Acknowledgement. The research leading to these results has been conducted within a collaboration between VITO and KU Leuven for improving the meteorological parameters for urban air-quality simulations. It was supported by the program Science for a Sustainable Development (SSD) of the Belgian Science Policy Office (BELSPO) under contract number SD/CS/04A. It has received funding from the European Union 7th Framework Programme (FP7 2007-2013) under grant agreements no. 308299 and no. 308497. This research was undertaken with the assistance of resources provided at the NCI National Facility systems at the Australian National University through the National Computational Merit Allocation Scheme supported by the Australian Government. The computational resources and services used in this work were also provided by the Hercules Foundation and the Flemish Government - department EWI. Finally, we wish to thank two anonymous referees for their insightful suggestions.

Edited by: M. Van Roozendael

\section{References}

Alexandri, E. and Jones, P.: Developing a one-dimensional heat and mass transfer algorithm for describing the effect of green roofs on the built environment: Comparison with experimental results, Build. Environ., 42, 2835-2849, doi:10.1016/j.buildenv.2006.07.004, 2007.

Arnfield, A. J.: Two decades of urban climate research: a review of turbulence, exchanges of energy and water, and the urban heat island, Int. J. Climatol., 23, 1-26, doi:10.1002/joc.859, 2003.

Arya, S. P.: Introduction to micrometeorology, Academic Press, San Diego, CA, USA, 2nd edn edn., 2001.

Bohnenstengel, S. I., Evans, S., Clark, P. A., and Belcher, S. E.: Simulations of the London urban heat island, Q. J. Roy. Meteorol. Soc., 137, 1625-1640, doi:10.1002/qj.855, 2011.

Bowler, D. E., Buyung-Ali, L., Knight, T. M., and Pullin, A. S.: Urban greening to cool towns and cities: A systematic review of the empirical evidence, Landsc. Urb. Plan., 97, 147-155, doi:10.1016/j.landurbplan.2010.05.006, 2010.

Businger, J. A.: Transfer of momentum and heat in the planetary boundary layer, Proc. Symp. Arctic Heat Budget and Atmospheric Circulation, RM-5233-NSF, 305-331, 1966.

Cai, G., Du, M., Xue, Y., and Li, S.: Analysis of an Urban Heat Sink using Thermal Inertia Model from ASTER Data in Beijing, China, in: Geoscience and Remote Sensing Symposium, 2008. IGARSS 2008. IEEE International, III - 1346III - 1349, IEEE International, Boston, Massachusetts, USA, doi:10.1109/IGARSS.2008.4779609, 2008.

Cermak, J. E., Davenport, A. G., Plate, E. J., and Viegas, D. X.: Wind climate in cities, Kluwer, Dordrecht, the Netherlands, 772 pp., 1995.

Cheng, Y. G. and Brutsaert, W.: Flux-profile relationships for wind speed and temperature in the stable atmospheric boundary layer, Bound.-Lay. Meteorol., 114, 519-538, doi:10.1007/s10546-0041425-4, 2005.

Clapp, R. B. and Hornberger, G. M.: Empirical equations for some soil hydraulic properties, Water Resour. Res., 14, 601-604, doi:10.1029/WR014i004p00601, 1978.

Cosby, B. J., Hornberger, G. M., Clapp, R. B., and Ginn, T. R.: A Statistical Exploration of the Relationships of Soil Moisture Characteristics to the Physical Properties of Soils, Water Resour. Res., 20, 682, doi:10.1029/WR020i006p00682, 1984.

Cuxart, J., Holtslag, A. A. M., Beare, R. J., Bazile, E., Beljaars, A., Cheng, A., Conangla, L., Ek, M., Freedman, F., Hamdi, R., Kerstein, A., Kitagawa, H., Lenderink, G., Lewellen, D., Mailhot, J., Mauritsen, T., Perov, V., Schayes, G., Steeneveld, G.-J., Svensson, G., Taylor, P., Weng, W., Wunsch, S., and Xu, K.M.: Single-Column Model Intercomparison for a Stably Stratified Atmospheric Boundary Layer, Bound.-Lay. Meteorol., 118, 273-303, doi:10.1007/s10546-005-3780-1, 2006.

De Ridder, K.: Bulk Transfer Relations for the Roughness Sublayer, Bound.-Lay. Meteorol., 134, 257-267, doi:10.1007/s10546-0099450-y, 2010.

De Ridder, K. and Schayes, G.: The IAGL Land Surface Model, J. Appl. Meteor., 36, 167-182, doi:10.1175/15200450(1997)036<0167:TILSM>2.0.CO;2, 1997.

Demuzere, M., De Ridder, K., and van Lipzig, N. P. M.: Modeling the energy balance in Marseille: Sensitivity to roughness length parametrizations and thermal admittance, J. Geophys. Res., 113, $1-19,2008$. 
Dimoudi, A.: Vegetation in the urban environment: microclimatic analysis and benefits, Energ. Build., 35, 69-76, doi:10.1016/S0378-7788(02)00081-6, 2003.

Dyer, A. J.: The turbulent transport of heat and water vapour in an unstable atmosphere, Q. J. Roy. Meteor. Soc., 93, 501-508, doi:10.1002/qj.49709339809, 1967.

Garratt, J. R.: The atmospheric boundary layer, Cambridge University Press, UK, 1992.

Grimmond, C. S. B. and Oke, T. R.: Evapotranspiration rates in urban areas, AHS Publ., 259, 235-243, 1999.

Grimmond, C. S. B., Oke, T. R., and Timothy, R.: Heat Storage in Urban Areas: Local-Scale Observations and Evaluation of a Simple Model, J. Appl. Meteor., 38, 922-940, doi:10.1175/15200450(1999)038<0922:HSIUAL > 2.0.CO;2, 1999.

Gutman, G. and Ignatov, A.: The derivation of the green vegetation fraction from NOAA/AVHRR data for use in numerical weather prediction models, Int. J. Remote Sens., 19, 1533-1543, doi:10.1080/014311698215333, 1998.

Ha, K.-J. and Mahrt, L.: Radiative and turbulent fluxes in the nocturnal boundary layer, Tellus, 55A, 317-327, doi:10.1034/j.16000870.2003.00031.x, 2003.

Hamdi, R., Degrauwe, D., and Termonia, P.: Coupling the Town Energy Balance (TEB) Scheme to an Operational Limited-Area NWP Model: Evaluation for a Highly Urbanized Area in Belgium, Weather Forecast., 27, 323-344, doi:10.1175/WAF-D-1100064.1, 2012.

Harman, I. N. and Belcher, S. E.: The surface energy balance and boundary layer over urban street canyons, Q. J. Roy. Meteorol. Soc., 132, 2749-2768, doi:10.1256/qj.05.185, 2006.

Jain, A. K.: Fundamentals of Digital Image Processing, Prentice Hall, 1989.

Landsberg, H. E.: International Geophysics Series, Vol. 28: The urban climate, Academic Press, Londen, UK, 1981.

Lee, J. S.: Speckle suppression and analysis for synthetic aperture radar images, Opt. Eng., 25, 636-643, 1986.

Lemonsu, A. and Masson, V.: Simulation of a Summer Urban Breeze Over Paris, Bound.-Lay. Meteorol., 104, 463-490, doi:10.1023/A:1016509614936, 2002.

Lemonsu, A., Belair, S., and Mailhot, J.: The New Canadian Urban Modelling System: Evaluation for Two Cases from the Joint Urban 2003 Oklahoma City Experiment, Bound.-Lay. Meteorol., 133, 47-70, doi:10.1007/s10546-009-9414-2, 2009.

Lin, Y.-L.: Mesoscale Dynamics, Cambridge University Press, 2007.

Makar, A., Gravel, S., Chirkov, V., Strawbridge, K. B., Froude, F., Arnold, J., and Brook, J.: Heat flux, urban properties, and regional weather, Atmos Environ, 40, 2750-2766, 2006.

Oke, T.: The energetic basis of the urban heat island, Q. J. Roy. Meteorol. Soc., 108, 1-24, doi:10.1002/qj.49710845502, 1982.

Oke, T. R.: Boundary Layer Climates, Methuen and Co. Ltd, London, 2nd edn., 1987.

Oleson, K. W., Bonan, G. B., Feddema, J., and Jackson, T.: An examination of urban heat island characteristics in a global climate model, Int. J. Climatol., 31, 1848-1865, doi:10.1002/joc.2201, 2011.
Pielke, R. A.: Mesoscale Meteorological Modeling, Academic Press, San Diego, CA, USA, 2nd edn., 2002.

Press, W. H., Teukolsky, S. A., Vetterling, W. T., and Flannery, B. P.: Numerical recipes in FORTRAN: The art of scientific computing, Cambridge University Press, 2nd edn edn., 1992.

Ridders, C. J. F.: A new algorithm for computing a single root of a real continuous function, IEEE Trans. Circuits Syst., 26, 979980, 1979.

Rodell, M., Houser, P. R., Jambor, U., Gottschalck, J., Mitchell, K., Meng, C.-J., Arsenault, K., Cosgrove, B., Radakovich, J., Bosilovich, M., Entin, J. K., Walker, J. P., Lohmann, D., and Toll, D.: The Global Land Data Assimilation System, B. Am. Meteorol. Soc., 85, 381-394, doi:10.1175/BAMS-85-3-381, 2004.

Sarkar, A. and De Ridder, K.: The Urban Heat Island Intensity of Paris: A Case Study Based on a Simple Urban Surface Parametrization, Bound.-Layer Meteorol., 138, 511-520, doi:10.1007/s10546-010-9568-y, 2010.

Savijärvi, H.: Radiative and turbulent heating rates in the clearair boundary layer, Q. J. Roy. Meteorol. Soc., 132, 147-161, doi:10.1256/qj.05.61, 2006.

Steeneveld, G. J., Wokke, M. J. J., Groot Zwaaftink, C. D., Pijlman, S., Heusinkveld, B. G., Jacobs, A. F. G., and Holtslag, A. A. M.: Observations of the radiation divergence in the surface layer and its implication for its parameterization in numerical weather prediction models, J. Geophys. Res.: Atmos., 115, D06107, doi:10.1029/2009JD013074, 2010.

Sugawara, H. and Narita, K.: Roughness Length for Heat over an Urban Canopy, Theor. Appl. Climatol., 95, 291-299, 2008.

Van Weverberg, K., De Ridder, K., and Van Rompaey, A.: Modeling the Contribution of the Brussels Heat Island to a Long Temperature Time Series, J. Appl. Meteor. Climatol., 47, 976-990, doi:10.1175/2007JAMC1482.1, 2008.

Wittich, K.-P. and Hansing, O.: Area-averaged vegetative cover fraction estimated from satellite data, Int. J. Biometeorol., 38, 209-215, doi:10.1007/BF01245391, 1995.

Xue, M., Droegemeier, K. K., and Wong, V.: The Advanced Regional Prediction System (ARPS) - A multi-scale nonhydrostatic atmospheric simulation and prediction model. Part I: Model dynamics and verification, Meteorol. Atmos. Phys., 75, 161-193, doi:10.1007/s007030070003, 2000.

Xue, M., Droegemeier, K. K., Wong, V., Shapiro, A., Brewster, K., Carr, F., Weber, D., Liu, Y., and Wang, D.: The Advanced Regional Prediction System (ARPS) - A multi-scale nonhydrostatic atmospheric simulation and prediction tool. Part II: Model physics and applications, Meteorol. Atmos. Phys., 76, 143-165, doi:10.1007/s007030170027, 2001.

Zilitinkevich, S. S.: Dynamics of the atmospheric boundary layer, Leningrad Gidrometeor, 1970. 